\title{
Allocating carbon responsibility: the role of spatial production fragmentation
}

\section{CCEP Working Paper 1901 \\ February 2019}

\section{Zengkai Zhang}

College of Management and Economics, Tianjin University, China

China Academy of Energy, Environmental and Industrial Economics, China

\section{ZhongXiang Zhang}

Ma Yinchu School of Economics, Tianjin University, China

China Academy of Energy, Environmental and Industrial Economics, China

\section{Kunfu Zhu}

University of International Business and Economics, Beijing, China

\begin{abstract}
A number of studies have compared national carbon abatement responsibility under different carbon accounting schemes. However, the difficulty of the shift among different national carbon accounting schemes has rarely been quantitatively evaluated in the literature. Spatial production fragmentation over the recent decades has led to geographical separation among the primary inputs supplying regions, carbon emitting regions, and final consuming regions. The purpose of this paper is to reveal the effects of spatial production fragmentation on the shift from production-based to consumptionbased and income-based national carbon accounting. Based on both demand- and supply-driven input-output analytical frameworks, this paper analyses the allocation of carbon responsibility for embodied and enabled emissions along production chains over the period $1995-2009$. It was found that as much as $25 \%$ of embodied emissions and $20 \%$ of enabled emissions crossed national borders more than once in 2009. The shift among different carbon accounting schemes is not only related to the magnitude of trade related emissions but also related to border-crossing frequency associated with emissions embodied in or enabled by international trade. The increasingly fragmented production networks complicate the shift from production-based to consumption-based or incomebased accounting and weaken the effectiveness of consumption-based or income-based accounting.
\end{abstract}




\section{Keywords:}

National carbon accounting; Spatial production fragmentation; Border-crossing frequency; Embodied emissions; Enabled emissions

\section{JEL Classification:}

C67; F18; F64; O13; Q43; Q54; Q56

\section{Suggested Citation:}

Zhang, Z., Zhang, ZX. and Zhu, K. (2019), Allocating carbon responsibility: the role of spatial production fragmentation, CCEP Working Paper 1901, February 2019, Crawford School of Public Policy, The Australian National University.

\section{Address for Correspondence:}

ZhongXiang Zhang

Ma Yinchu School of Economics

Tianjin University

92 Weijin Road

Tianjin 300072, China

E-mail: : ZhangZX@tju.edu.cn

The Crawford School of Public Policy is the Australian National University's public policy school, serving and influencing Australia, Asia and the Pacific through advanced policy research, graduate and executive education, and policy impact.

The Centre for Climate Economics \& Policy is an organized research unit at the Crawford School of Public Policy, The Australian National University. The working paper series is intended to facilitate academic and policy discussion, and the views expressed in working papers are those of the authors. Contact for the Centre: Prof Frank Jotzo, frank.jotzo@anu.edu.au 


\section{Introduction}

Production-based accounting (PBA) is a metric adopted by most climate policies (Marques et al., 2012; Zhang, 2012a and 2012b). To reflect suppliers' and consumers' responsibility, the literature further proposes consumption-based accounting (CBA), which measures emissions driven by regional final consumption (Afionis et al., 2017; Davis and Caldeira, 2010; Druckman and Jackson, 2009; Feng et al., 2013; Guo et al., 2012; Hertwich and Peters, 2009; Liu, 2014; Peters, 2008; Peters et al., 2011; Su and Ang, 2011; Weber et al., 2008) and income-based accounting (IBA), which measures emissions enabled by regional primary inputs (Blanca Gallego and Lenzen, 2005; Lenzen and Murray, 2010; Liang et al., 2017, 2016; Marques et al., 2012). The key steps of shifting from PBA to CBA and IBA lie in relocating carbon responsibility along global supply chains. However, the spatial production fragmentation over the recent decades has led to geographical separation among the primary inputs suppliers, carbon emitters, and final consumers. This means that it may become increasingly challenging to shift among different carbon accounting schemes because of regional jurisdiction (Turner et al., 2011). Therefore, the purpose of this paper is to reveal the effects of spatial production fragmentation on the allocation of carbon abatement responsibility ${ }^{2}$ along global production networks.

What matters for the relocation of carbon responsibility along global value chains? We illustrate this issue with a simple example. The ability to throw a stone across a river is determined not only by the weight of the stone but also by the width of the river. Two sides of the river can be viewed as the source and destination regions of carbon transfer. The stone represents the reallocated carbon responsibility. To the best of our knowledge, the existing literature focuses primarily on the magnitude of traderelated emissions (Davis et al., 2011; Davis and Caldeira, 2010; Hertwich and Peters, 2009; Jakob and Marschinski, 2012; Peters et al., 2011; Weber and Matthews, 2007; Zhang et al., 2014). However, less attention has been paid to the economic length of global supply chain. Due to spatial production fragmentation, the supplier, producer, and consumer regions may be far away from each other in global supply chains, and it

\footnotetext{
${ }^{2} \mathrm{PBA}, \mathrm{CBA}$, and IBA are respectively corresponding to territory, upstream, and downstream responsibility (Lenzen and Murray, 2010; Marques et al., 2012).
} 
is difficult to reallocate carbon responsibility among them. Thus, this paper attempts to enrich the existing literature by analyzing the shift from PBA to CBA and IBA from the perspective of spatial production fragmentation.

In this paper, the width of the river represents the economic distance between two countries in global supply chains. A variety of studies (Antràs et al., 2012; Dietzenbacher et al., 2005; Dietzenbacher and Romero, 2007; Fally, 2012; Ni et al., 2016; Wang et al., 2014) evaluate a country's relative position in global value chains by the Average Production Length (APL) proposed by Dietzenbacher et al. (2005). However, Oosterhaven and Bouwmeester (2013) warn that the APL is only suitable for pure industry linkage and cannot be used to compare different economies. In addition, this present paper focuses mainly on the regional jurisdiction that can be reflected by the number of countries that are involved in the global production chains. The APL cannot be directly used in this paper to evaluate the economic distance between pairs of countries. To address this problem, this paper makes a decomposition of the APL and uses the average number of border-crossing frequency (BCF) associated with trade-related emissions to evaluate the economic length between different agents.

A greater BCF associated with trade-related emissions means that the reallocated carbon responsibility has to be transferred between different countries or regions multiple times. The data quality and availability of the trading partners cannot be assured as an increasing number of countries are involved in the production of traded products (Afionis et al., 2017). This would result in a great uncertainty and hinder the shift from PBA to CBA or IBA (Peters, 2008; Peters and Hertwich, 2008a). In addition, some countries are not relatively active in responding to the climate change. The longer the carbon transfer path is, the greater is the possibility that the reallocation of carbon responsibility is hindered because of some countries' noncooperation. In other words, a greater BCF means that the supplier, producer, and consumer regions are farther away from each other in global supply chains and that it is more difficult to shift national carbon accounting. The literature has noticed the geographical separation among supplier, producer, and consumer regions (Marques et al., 2013). Against the globalization background, a full picture of carbon emissions embodied in global supply chains becomes more and more important for policy makers to determine regional carbon responsibility. A policy implication of this study 
lies in providing a new insight (e.g., border-crossing frequency associated with traderelated emissions) for understanding carbon responsibility allocation along global supply chains.

The measure of BCF associated with traded products is first analyzed in the research area of global value chains (Muradov, 2016; Wang et al., 2017). Zhang et al. (2017) propose another calculation method and first defined the BCF associated with embodied emissions based on the demand-pull input-output model. Tracing embodied and enabled emissions along the global supply chain is a primary condition for shifting from PBA to CBA and IBA. This paper extends Zhang et al.'s study (2017) to supply-push input-output model and proposes the BCF associated with enabled emissions. More specifically, this study calculates BCFs associated with embodied and enabled emissions by dividing the Leontief and Ghosh inverse matrix. In addition, the study introduces the structural path analysis (SPA) (Kanemoto et al., 2014; Lenzen et al., 2012; Meng et al., 2015; Peters and Hertwich, 2007; Skelton et al., 2011) to map emissions enabled by cross-border value chains and emissions embodied in cross-border trade flows.

This paper builds on previous studies that analyze the relationship and divergence among different national carbon accounting schemes. Based on who (i.e., producer, consumer, extractor or income beneficiary) is responsible for the trade-related emissions, there are four types of accounting schemes: PBA, CBA, IBA and EBA (extraction-based accounting) (Steininger et al., 2016). CBA is equal to PBA plus foreign upstream emissions embodied in imports minus domestic upstream emissions embodied in exports (Afionis et al., 2017; Arce et al., 2016; Davis et al., 2011; Peters and Hertwich, 2008b; Su and Ang, 2014). IBA is equal to PBA plus foreign downstream emissions enabled by exports minus domestic downstream emissions enabled by imports (Liang et al., 2017, 2016; Marques et al., 2012). EBA is different from PBA in how to allocate emissions related to traded fuels (Steininger et al., 2016). However, the fuel production process is relatively less fragmented spatially. Therefore, this study focuses mainly on the transfer from PBA to CBA and IBA. In addition, we believe that this study may help better understand the difficulty of sharing carbon responsibility along global supply chains (Gallego and Lenzen, 2005; Lenzen et al., 2007). 
This paper is organized into five sections. Section 2 describes the methodology. Section 3 presents the simulation results. Discussions and conclusions are presented in Sections 4 and 5, respectively.

\section{Methodology}

This paper adopts a global multiregional input-output model (GMRIO) to trace traderelated emissions along global supply chains. The GMRIO framework is presented in Table 1.

Table 1 Global multiregional input-output framework

\begin{tabular}{|c|c|c|c|c|c|c|c|c|}
\hline \multirow{3}{*}{\multicolumn{2}{|c|}{ Outputs }} & \multicolumn{3}{|c|}{ Intermediate demand } & \multicolumn{3}{|c|}{ Final demand } & \multirow{3}{*}{ Output } \\
\hline & & \multirow{2}{*}{$\begin{array}{c}\text { Country1 } \\
\text { Sector1...Sector N } \\
\end{array}$} & \multirow{2}{*}{$\ldots$} & \multirow{2}{*}{$\begin{array}{c}\text { Country G } \\
\text { Sector1...Sector N } \\
\end{array}$} & \multirow{2}{*}{ Country1 } & \multirow{2}{*}{$\cdots$} & \multirow{2}{*}{ Country G } & \\
\hline & & & & & & & & \\
\hline \multirow{3}{*}{ 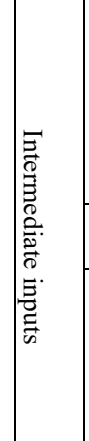 } & $\begin{array}{l}\text { Sector } 1 \\
\vdots \\
\text { Sector } \mathrm{N}\end{array}$ & $Z^{11}$ & $\ldots$ & $Z^{1 G}$ & $Y^{11}$ & $\ldots$ & $Y^{1 G}$ & $X^{1}$ \\
\hline & $\vdots$ & $\vdots$ & $\ddots$ & $\vdots$ & $\vdots$ & $\ddots$ & $\vdots$ & $\vdots$ \\
\hline & $\begin{array}{l}\text { Sector } 1 \\
\vdots \\
\text { Sector } \mathrm{N}\end{array}$ & $Z^{G 1}$ & . & $Z^{G G}$ & $Y^{G 1}$ & $\ldots$ & $Y^{G G}$ & $X^{G}$ \\
\hline \multicolumn{2}{|c|}{ Value added } & $V^{1}$ & $\ldots$ & $V^{G}$ & & & & \\
\hline \multicolumn{2}{|c|}{ Output } & $\left(X^{1}\right)^{\prime}$ & $\ldots$ & $\left(X^{G}\right)^{\prime}$ & & & & \\
\hline \multicolumn{2}{|c|}{ Emissions } & $E^{1}$ & $\ldots$ & $E^{G}$ & & & & \\
\hline
\end{tabular}

The world is composed of $G$ countries, with each country separated into $N$ sectors. The intermediate input matrix from country $s(s=1, \cdots, G)$ to country $r(r=1, \cdots, G)$ is denoted by $Z^{s r}$. $Y^{s r}$ represents the final product exports from country $s$ to country $r$. The final output of country $s$ is represented by $X^{s}$. The value added of country $s$ is represented by $V^{s}$. The emissions of country $s$ are represented by $E^{s}$. We define $F$ as a $G N \times G N$ diagonal matrix with sectoral carbon intensity in each country as its elements. Based on the Leontief and Ghosh models, we obtain the emissions $(\hat{E})$ 
that are induced by the final demand of different countries and the emissions $(\tilde{E})$ that are enabled by value added of different countries, respectively.

$$
\begin{aligned}
& \hat{E}=F(I-A)^{-1} \hat{Y} \\
& \tilde{E}=F\left(I-H^{\prime}\right)^{-1} \hat{V}
\end{aligned}
$$

where $A=\left[\begin{array}{cccc}A^{11} & A^{12} & \cdots & A^{1 G} \\ A^{21} & A^{22} & \cdots & A^{2 G} \\ \vdots & \vdots & \ddots & \vdots \\ A^{G 1} & A^{G 2} & \cdots & A^{G G}\end{array}\right]$ is the $G N \times G N$ input-output coefficient matrix (the elements satisfy $\left.a_{i j}=z_{i j} / x_{j}\right), \quad H=\left[\begin{array}{cccc}H^{11} & H^{12} & \cdots & H^{16} \\ H^{21} & H^{22} & \cdots & H^{2 G} \\ \vdots & \vdots & \ddots & \vdots \\ H^{G 1} & H^{G 2} & \cdots & H^{G G}\end{array}\right]$ is the $G N \times G N$ direct distribution coefficient matrix (the elements satisfy $\left.h_{i j}=Z_{i j} / x_{i}\right), \hat{Y}=\left[\begin{array}{cccc}\hat{Y}^{11} & \hat{Y}^{12} & \ldots & \hat{Y}^{1 G} \\ \hat{Y}^{11} & \hat{Y}^{22} & \cdots & \hat{Y}^{2 G} \\ \vdots & \vdots & \ddots & \vdots \\ \hat{Y}^{G 1} & \hat{Y}^{G 2} & \cdots & \hat{Y}^{G G}\end{array}\right]$, $\hat{Y}^{s r}$ is the diagonal matrix of $Y^{s r}, \hat{V}=\left[\begin{array}{cccc}\left(V^{1}\right)^{\prime} & 0 & \cdots & 0 \\ 0 & \left(V^{2}\right)^{\prime} & \cdots & 0 \\ \vdots & \vdots & \ddots & \vdots \\ 0 & 0 & \cdots & \left(V^{G}\right)^{\prime}\end{array}\right]$ is a $G N \times G$ diagonal matrix with the sectoral value added in each country as its elements. From the horizontal perspective of $\hat{E}$, we could obtain a certain country's production-based emissions induced by the final demands of other countries. From the vertical perspective of $\hat{E}$, we could obtain the emissions induced by the final demand of a certain country, which corresponds to consumption-based accounting. From the horizontal perspective of $\tilde{E}$, we could obtain a certain country's production-based emissions enabled by value added from each country. From the vertical perspective of $\tilde{E}$, we could obtain the emissions enabled by value added of a certain country, which corresponds to the income-based accounting.

Being in line with the logic of the literature (Zhang et al., 2017a), this paper deconstructs national emissions into two parts. The first one is induced by pure domestic economic activity, and the second represents emissions embodied in international trade flows.

$$
\begin{aligned}
& \hat{E}=F L^{D} \hat{Y}^{D}+\underbrace{F L^{D} \hat{Y}^{E}+F L^{D} A^{E} B \hat{Y}}_{\text {Embodied Emissions(EEX) }} \\
& \tilde{E}=F G^{D} \hat{V}+\underbrace{F G^{D} H^{E} G \hat{V}}_{\text {Enabled Emissions(EEI) }}
\end{aligned}
$$


where $L^{D}=\left[\begin{array}{cccc}L^{11} & 0 & \cdots & 0 \\ 0 & L^{22} & \cdots & 0 \\ \vdots & \vdots & \ddots & \vdots \\ 0 & 0 & \cdots & L^{G G}\end{array}\right], L^{S S}=\left(I-A^{S S}\right)^{-1}$ represents the local Leontief inverse matrix of region $S, \hat{Y}^{D}=\left[\begin{array}{cccc}\hat{Y}^{11} & 0 & \cdots & 0 \\ 0 & \hat{Y}^{22} & \cdots & 0 \\ \vdots & \vdots & \ddots & \vdots \\ 0 & 0 & \cdots & \hat{Y}^{G G}\end{array}\right]$ represents the final outputs that are used to satisfy domestic final demand, $\hat{Y}^{E}=\hat{Y}-\hat{Y}^{D}=\left[\begin{array}{cccc}0 & \hat{Y}^{12} & \cdots & \hat{Y}^{1 G} \\ \hat{Y}^{21} & 0 & \cdots & \hat{Y}^{2 G} \\ \vdots & \vdots & \ddots & \vdots \\ \hat{Y}^{G 1} & \hat{Y}^{G 2} & \cdots & 0\end{array}\right]$ represents the final products exports, $B=(I-A)^{-1}$ represent the Leontief inverse matrix, and $A^{E} B \hat{Y}$ represents the exports of intermediate products. International trade is represented by $T_{e x}=Y^{E}+A^{E} B \hat{Y}$. According to Wang et al.'s study (2015), the relation between $B$ and $L^{D}$ satisfies $B=L^{D}+L^{D} A^{E} B$, where $A^{E}=\left[\begin{array}{cccc}0 & A^{12} & \cdots & A^{1 G} \\ A^{21} & 0 & \cdots & A^{2 G} \\ \vdots & \vdots & \ddots & \vdots \\ A^{G 1} & A^{G 2} & \cdots & 0\end{array}\right]$. The second and third parts of equation (2a) represent regional emissions embodied in international trade flows ( $E E X)$, respectively. $G=\left(I-H^{\prime}\right)^{-1}$ represents the change in sectoral outputs due to unit change in value added. We define $G^{s s}=\left(I-H^{s s^{\prime}}\right)^{-1}$ and $G^{D}=\left[\begin{array}{cccc}G^{11} & 0 & \cdots & 0 \\ 0 & G^{22} & \cdots & 0 \\ \vdots & \vdots & \ddots & \vdots \\ 0 & 0 & \cdots & G^{G G}\end{array}\right]$. The relation between $G$ and $G^{D}$ is represented by the equation $G=G^{D}+G^{D} H^{E} G \quad, \quad$ where $\quad H^{E}=\left[\begin{array}{cccc}0 & H^{12} & \cdots & H^{1 G} \\ H^{21} & 0 & \cdots & H^{2 G} \\ \vdots & \vdots & \ddots & \vdots \\ H^{G 1} & H^{G 2} & \cdots & 0\end{array}\right]$. Additionally, $T_{i m}=H^{E} G \hat{V}$ represents the exports of intermediate products. The second part of equation (2b) represents a country's emissions enabled by international imports. Intermediate products may cross national borders multiple times. This paper further deconstructs national emissions based on border crossing frequency associated with trade flows.

$$
\begin{aligned}
& \hat{E}=\underbrace{F L^{D} \hat{Y}^{D}}_{B C F=0}+\underbrace{F L^{D} Z Y^{D}+F L^{D} Y^{E}}_{B C F=1}+\underbrace{F L^{D} Z^{2} Y^{D}+F L^{D} Z Y^{E}}_{B C F=2}+\underbrace{F L^{D} Z^{3} Y^{D}+F L^{D} Z^{2} Y^{E}}_{B C F=3}+\cdots \\
& \tilde{E}=\underbrace{F G^{D} \hat{V}}_{B C F=0}+\underbrace{F G^{D} W \hat{V}}_{B C F=1}+\underbrace{F G^{D} W^{2} \hat{V}}_{B C F=2}+\underbrace{F G^{D} W^{3} \hat{V}}_{B C F=3}+\cdots
\end{aligned}
$$

where $Z=A^{E} L^{D}$, and it satisfies $B=L^{D}(I-Z)^{-1}{ }^{3} . F L^{D} Y^{E}$ represents the carbon emissions embodied in final product trade, which cross borders once. $F L^{D}(Z)^{t} Y^{D}$

${ }^{3}$ According to $B=L^{D}+L^{D} A^{E} B$, we obtain 
represents the carbon emissions embodied in intermediate product trade flows. The intermediate products cross borders $t$ times and the final products are absorbed by the country that produces them. $F L^{D}(Z)^{t} Y^{E}$ represents the carbon transfer that is related to both intermediate and final products trade. The intermediate products cross regional borders $t$ times and the final products cross regional borders once. $W=H^{E} G^{D}$, and it satisfies $G=G^{D}(I-W)^{-1}{ }^{4} . \quad F G^{D} W^{t} \hat{V}$ represents carbon emissions enabled by international imports which cross national borders $t$ times.

There exist different cross-border trade flows. Which one plays the most important role in the bilateral carbon transfer? This paper seeks to answer this question based on structural path analysis from a spatial perspective. Taking the Leontief input-output model as an example, we suppose $L_{s}^{D}=\left[\begin{array}{cccc}p_{1} L_{11} & 0 & \cdots & 0 \\ 0 & p_{2} L_{22} & \cdots & 0 \\ \vdots & \vdots & \ddots & \vdots \\ 0 & 0 & \cdots & p_{G} L_{G G}\end{array}\right], Y_{s}^{D}=\left[\begin{array}{cccc}p_{1} Y_{11} & 0 & \cdots & 0 \\ 0 & p_{2} Y_{22} & \cdots & 0 \\ \vdots & \vdots & \ddots & \vdots \\ 0 & 0 & \cdots & p_{G} Y_{G G}\end{array}\right]$, $\left(p_{m}=I\right.$ if $m=s$, otherwise, $\left.p_{m}=0\right)$, and $Z_{s r}=\left[\begin{array}{cccc}0 & h_{12} A_{12} L_{22} & \cdots & h_{1 G} A_{1 G} L_{G G} \\ h_{21} A_{21} L_{11} & 0 & \cdots & h_{2 G} A_{2 G} L_{G G} \\ \vdots & \vdots & \ddots & \vdots \\ h_{G 1} A_{G 1} L_{11} & h_{G 2} A_{G 2} L_{22} & \cdots & 0\end{array}\right]$ and $Y_{s r}^{E}=\left[\begin{array}{cccc}0 & h_{12} Y_{12} & \cdots & h_{1 G} Y_{1 G} \\ h_{21} Y_{21} & 0 & \cdots & h_{2 G} Y_{2 G} \\ \vdots & \vdots & \ddots & \vdots \\ h_{G 1} Y_{G 1} & h_{G 2} Y_{G 2} & \cdots & 0\end{array}\right] \quad\left(h_{m n}=I\right.$ if $m=s$ and $n=r$, otherwise, $\left.h_{m n}=0\right)$. The direct carbon transfer from country $s$ to country $r$ is represented by $F L_{s}^{D} Z_{s r} Y_{r}^{D}+F L_{s}^{D} Y_{s r}^{E}$. The exported products of country $s$ may be first processed in country $t$ before they are finally absorbed by country $r$. The corresponding carbon

$$
\begin{aligned}
B & =L^{D}+L^{D} A^{E} B \\
& =L^{D}+L^{D} A^{E}\left(L^{D}+L^{D} A^{E} B\right) \\
& =L^{D}+L^{D} A^{E} L^{D}+L^{D} A^{E} L^{D} A^{E} L^{D}+L^{D} A^{E} L^{D} A^{E} L^{D} A^{E} L^{D}+\ldots \ldots \\
& =L^{D}+L^{D} Z+L^{D} Z^{2}+L^{D} Z^{3}+\ldots \ldots \\
& =L^{D}(I-Z)^{-1}
\end{aligned}
$$

${ }^{4}$ According to $G=G^{D}+G^{D} H^{E} G$, we obtain

$$
\begin{aligned}
G & =G^{D}+G^{D} H^{E} G \\
& =G^{D}+G^{D} H^{E}\left(G^{D}+G^{D} H^{E} G\right) \\
& =G^{D}+G^{D} H^{E} G^{D}+G^{D} H^{E} G^{D} H^{E} G^{D}+G^{D} H^{E} G^{D} H^{E} G^{D} H^{E} G^{D}+\ldots \ldots \\
& =G^{D}+G^{D} W+G^{D} W^{2}+G^{D} W^{3}+\ldots \ldots \\
& =G^{D}(I-W)^{-1}
\end{aligned}
$$


transfer path is $F L_{s}^{D} Z_{s t} Z_{t r} Y_{r}^{D}+F L_{s}^{D} Z_{s t} Y_{t r}^{E}$. Similarly, we could obtain other carbon transfer paths from country $s$ to country $r$. Although there are an infinite number of structural paths, the magnitude of embodied emissions would decrease as the carbon transfer length becomes longer. Therefore, it is possible to find the most important carbon transfer paths. Summing of the embodied emissions of all structural paths yields the total carbon transfer from country $s$ to country $r$. Based on Ghosh inputoutput model, we could implement structural path analysis from a spatial perspective to clarify the cross-border value chains that correspond to different BCF and different magnitude of enabled emissions. The average length of carbon transfer is

$$
\begin{gathered}
A L_{-} L=\frac{F B T_{e x}}{F L^{D} T_{e x}} \\
A L_{-} G=\frac{F G T_{i m}}{F G^{D} T_{i m}}
\end{gathered}
$$

The final consumer's (raw material supplier's) influential power on the carbon emitter may decrease exponentially with the BCF associated with embodied (enabled) emissions because of international differences in politics, economy, and culture. In

$$
\begin{aligned}
A L_{-} L & =\frac{F L^{D}\left(Z+2 Z^{2}+\ldots\right) Y^{D}+F L^{D}\left(I+2 Z+3 Z^{2}+\ldots\right) Y^{E}}{F L^{D} T_{e x}} \\
& =\frac{F L^{D}\left((I-Z)^{-1}\right)^{2} Y-F L^{D}(I-Z)^{-1} Y^{D}}{F L^{D} T_{e x}} \\
& =\frac{F B\left((I-Z)^{-1} Y-Y^{D}\right)}{F L^{D} T_{e x}} \\
& =\frac{F B\left(Y^{E}+\left(Z+Z^{2}+\ldots\right) Y\right)}{F L^{D} T_{e x}} \\
& =\frac{F B\left(Y^{E}+A^{E} B Y\right)}{F L^{D} T_{e x}} \\
& =\frac{F B T_{e x}}{F L^{D} T_{e x}} \\
A L_{-} G & =\frac{F G^{D}\left(W+2 W^{2}+\ldots\right) \hat{V}}{F G^{D} T_{i m}} \\
& =\frac{F G^{D}\left((I-W)^{-1}\right)^{2} \hat{V}-F G^{D}(I-W)^{-1} \hat{V}}{F G^{D} T_{i m}} \\
& =\frac{F G\left((I-W)^{-1} \hat{V}-\hat{V}\right)}{F G^{D} T_{i m}} \\
& =\frac{F G\left(W+W^{2}+\ldots\right) \hat{V}}{F G^{D} T_{i m}} \\
& =\frac{F G H^{E} G \hat{V}}{F G^{D} T_{i m}} \\
& \frac{F G T_{i m}}{F G^{D} T_{i m}} \\
6 &
\end{aligned}
$$


other words, spatial production fragmentation hinders the environmental effectiveness of CBA and IBA. This paper assumes that the final consumer's and primary input supplier's influential power on the embodied and enabled emissions are $\alpha^{B C F}$ and $\beta^{B C F}$, respectively. $0<\alpha \leq 1$, and $0<\beta \leq 1$. If $\alpha=1$ and $\beta=1$, we obtain the traditional $\mathrm{CBA}$ and IBA. Otherwise, the influential power of the final consumer region and the raw material supplier region on the carbon emitter can be calculated by

$$
\begin{aligned}
& \hat{E}_{-} b c f=F L^{D} \hat{Y}^{D}+F L^{D} \alpha Z(I-\alpha Z)^{-1} Y^{D}+F L^{D} \alpha(I-\alpha Z)^{-1} Y^{E} \\
& \tilde{E}_{-} b c f=F G^{D} \hat{V}+F G^{D} \beta W(I-\beta W)^{-1} \hat{V}
\end{aligned}
$$

There are a number of different sources of inter-country input-output tables, such as the World Input-Output Database (WIOD) (Timmer et al., 2015), the multi-region input-output table based on the Global Trade Analysis Project Database (Andrew and Peters, 2013), and the Eora multi-region input-output table database (Lenzen et al., 2012). The quantitative calculation of this study is based on the WIOD, which adopted the recommended residence principle for emissions allocation (Zhang et al., 2017b). The WIOD divides the world into 41 countries/regions, and each country has 35 sectors (the abbreviations are presented in Appendixes A and B). The WIOD only provides national carbon emissions by sector over the period 1995-2009. Therefore, this paper focuses primarily on the effect of spatial production fragmentation on the allocation of carbon responsibility along global supply chains over the period 19952009. The robustness analysis of this study is based on the Eora multi-region inputoutput table database, which covers as much as 190 countries or regions (Appendix $\mathrm{G})$.

\section{Results}

This section first compares regional carbon inventories under the three different carbon accounting schemes. The shift from PBA to CBA and IBA means reallocating regional carbon responsibility, which is explained by both the volume of carbon transfer and the BCF associated with trade-related emissions. This study shows that spatial production fragmentation makes the shift of carbon responsibility increasingly challenging over the period 1995-2009, suggesting that spatial production fragmentation decreases the effectiveness of CBA and IBA. 


\subsection{Comparisons of carbon accounting schemes}

This study calculates regional carbon responsibility under PBA, CBA and IBA according to equations (3) and (9). The results are presented in Figure 1.

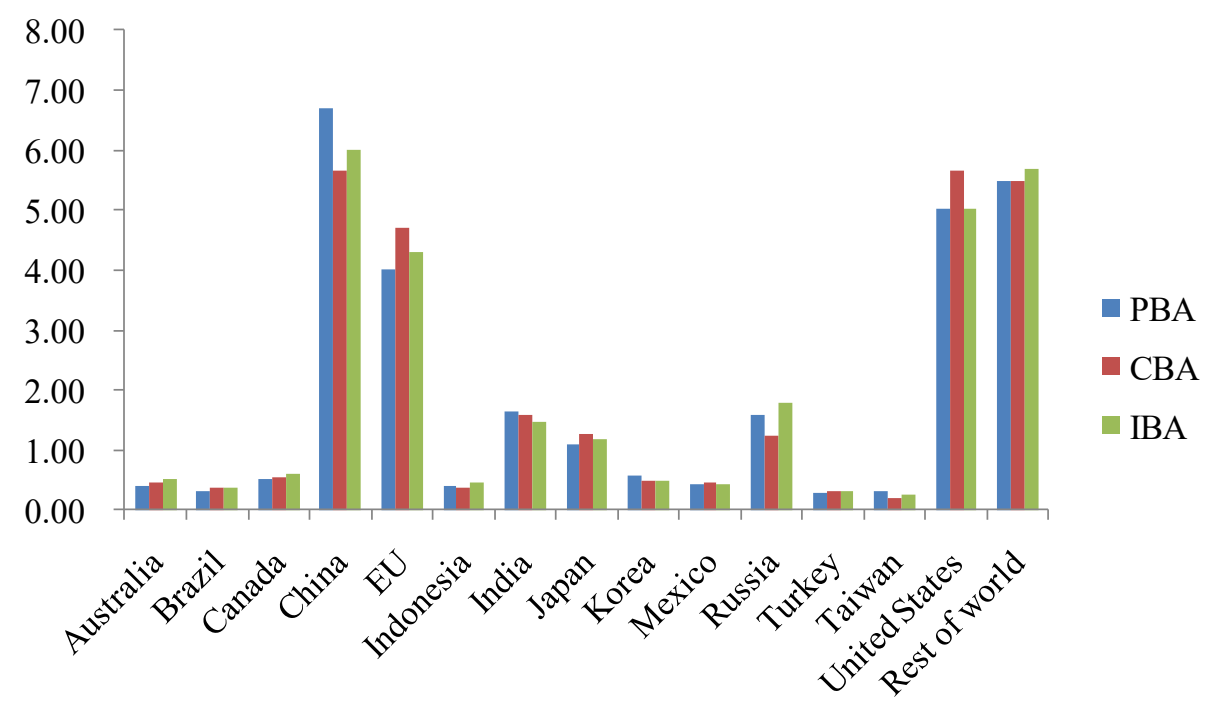

Figure 1 National carbon emissions under PBA, CBA and IBA in 2009

As shows in Figure 1, China is the largest carbon emitter and faces the greatest carbon responsibility under PBA, followed by the USA and EU. However, a large share of China's emissions are generated to produce products for the final consumption of the developed countries. Therefore, CBA frameworks tend to place more carbon responsibility upon the developed countries, such as the USA, EU, and Japan. Meanwhile, CBA would lower the carbon responsibility of the developing countries, such as China, India, and Russia. The difference between PBA and CBA lies in the allocation of carbon responsibility for emissions embodied in international trade. The developing countries and countries with economies in transition, such as China, Russia, and India, tend to be net carbon exporters (the magnitude of embodied emissions in exports is greater than the magnitude of embodied emissions in imports). Therefore, carbon responsibility of the developing countries under CBA is lower than that under PBA. By comparison, developed countries, such as the USA and EU tend to be net carbon importers and face greater carbon responsibility under CBA.

The difference between PBA and IBA lies in the allocation of carbon responsibility for emissions enabled by international trade. The results show that the resource 
exporting countries tend to face a greater scale of emissions enabled by exports rather than that enabled by imports. For instance, Russia, Canada and Australia are important suppliers of raw materials that are exported to other countries and used as essential inputs to industrial production. Therefore, these three countries would bear greater carbon responsibility under IBA than PBA. China not only imports a large number of raw materials but also imports a large amount of intermediate products from developed countries, such as Japan and EU. Therefore, IBA would place greater carbon responsibility upon Japan and EU than that under PBA. In addition, China would face a noticed decrease in carbon responsibility when the national carbon accounting shifts from PBA to IBA. There is no marked change in the carbon responsibility of the United States under PBA and IBA.

The key distinction among different carbon accounting schemes lies in the allocation of carbon responsibility on trade-related emissions. According to equations (4) and (10), we calculate the volume of each region's trade-related emissions under different carbon accounting schemes. The results are presented in Appendix C. However, the allocation of regional carbon responsibility is not only related to the volume of traderelated emissions but is also related to border-crossing frequency associated with traded emissions. From these two perspectives, this paper further examines the allocation of embodied and enabled emissions when the regional carbon accounting scheme shifts from PBA to CBA and IBA.

\subsection{Allocations of regional carbon responsibility}

According to equations (5) and (11), we deconstruct trade-related emissions by the border-crossing frequency. When the carbon accounting scheme is shifted from PBA to $\mathrm{CBA}$ or IBA, the regional reallocation of trade-related emissions is presented in Figure 2. 


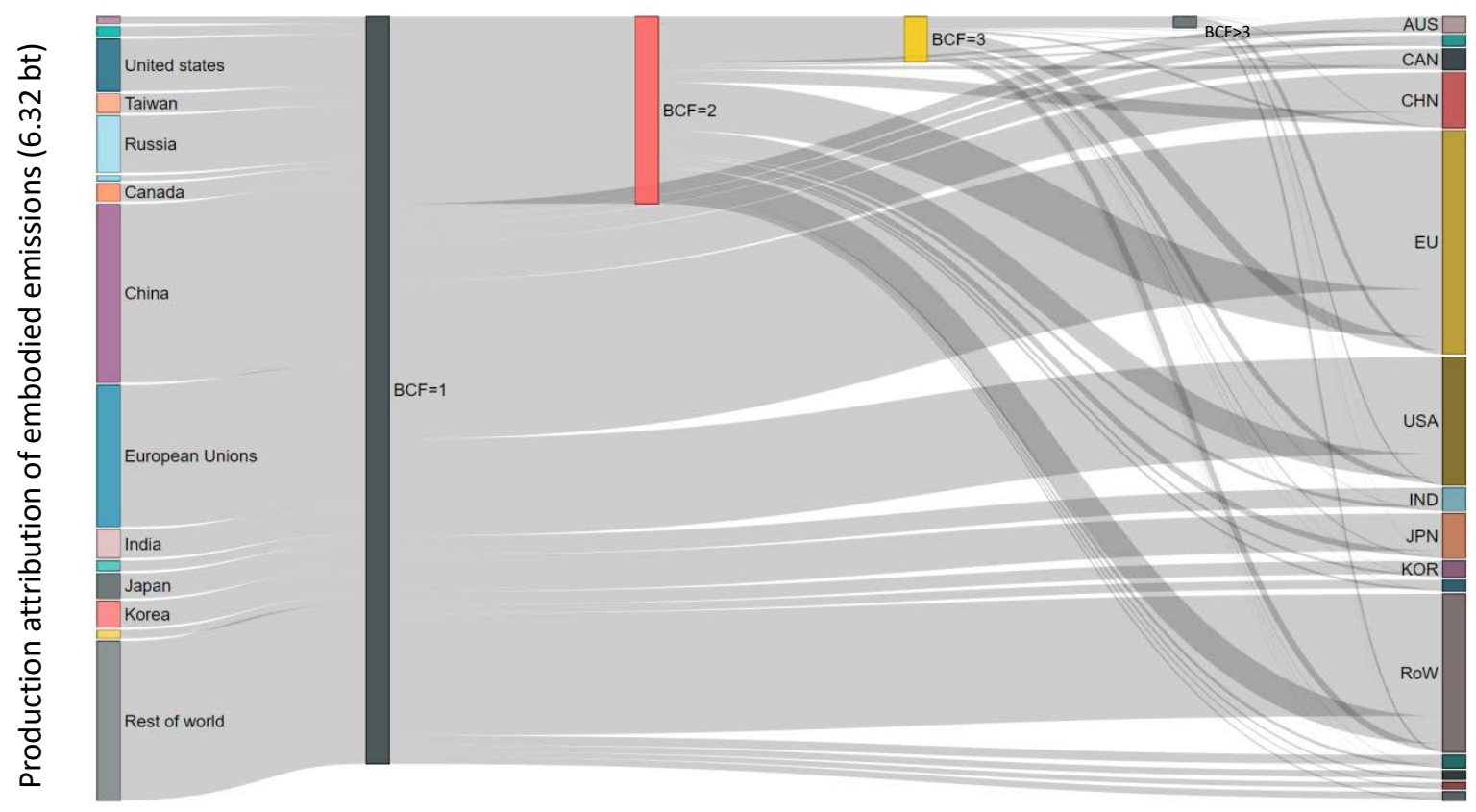

a) Allocation of embodied emissions in cross-border trade flows

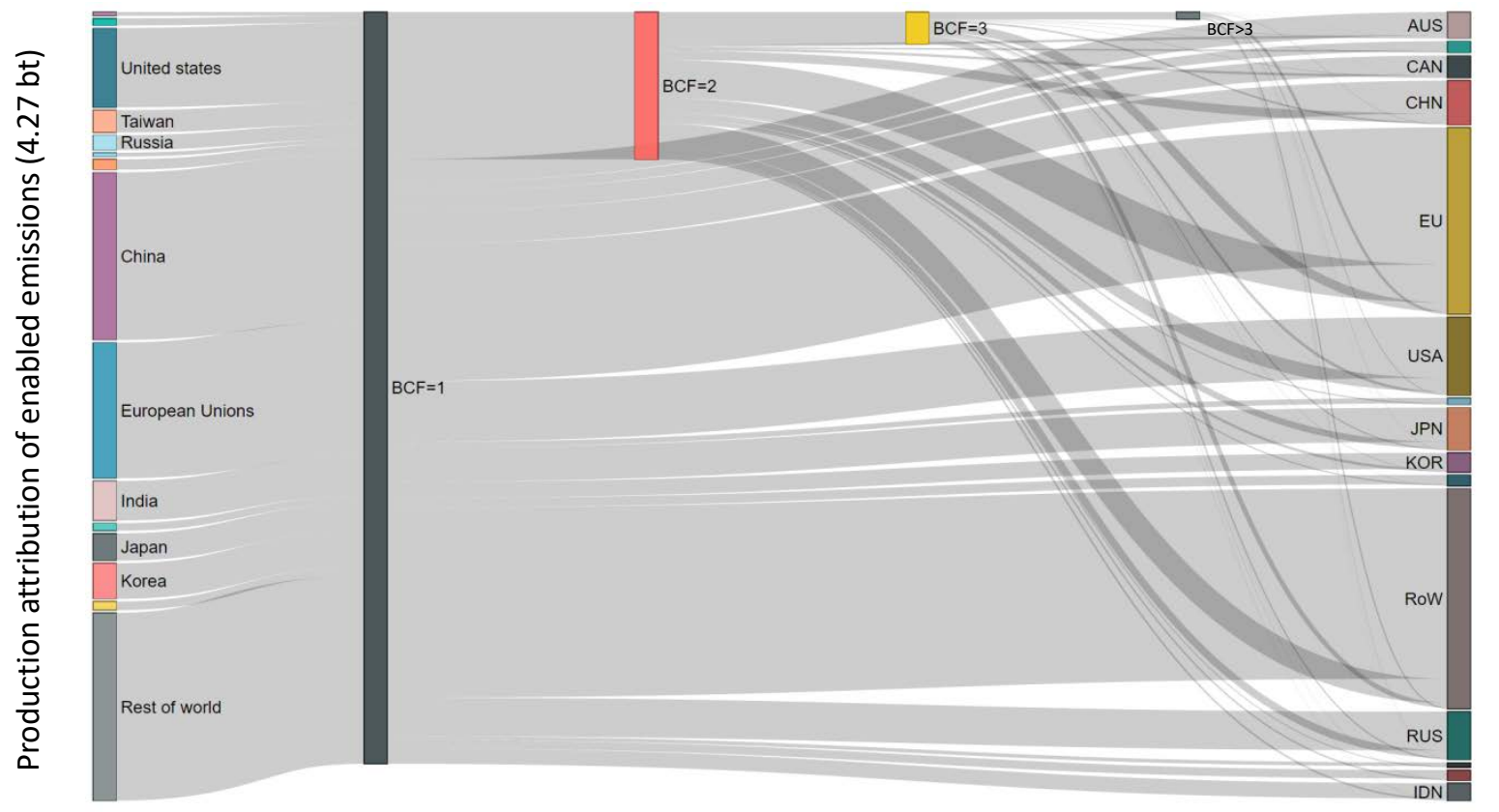

b) Allocation of enabled emissions by cross-border value chains

Figure 2 Sankey diagram of the world embodied and enabled emissions in 2009

Figure $2 \mathrm{a}$ presents the national attribution of embodied emissions under PBA and CBA. The left-hand side of the map shows the magnitude of national emissions induced by international trade. The right-hand side of the map presents the embodied emissions that are generated for the final consumption of each country. The gross 
magnitude of emissions embodied in cross-border trade flows was 6.32 billion tons in 2009. China is the largest carbon exporter ( 1.51 billion tons), which is mainly driven by the final demand of developed countries. The final consumption of the USA, EU, and Japan play the dominant role in driving carbon emissions embodied in international trade. Therefore, these countries would bear greater carbon responsibility under CBA than that under PBA (more detailed information is provided in Appendix D). We further classify different types of carbon transfer by the BCF associated with embodied emissions. The results show that $74.98 \%$ of interregional carbon transfer cross national borders once, $18.99 \%$ of interregional carbon transfer cross national borders twice, $4.58 \%$ of the interregional carbon transfer cross national borders three times, and $1.45 \%$ of the interregional carbon transfer cross national borders four times or more.

Figure 2.b presents the national attribution of enabled emissions under PBA and IBA. The left-hand side of the map shows the magnitude of national emissions enabled by cross-border value chains. The right-hand side of the map presents the magnitude of emissions enabled by a country's value-added. The gross magnitude of emissions enabled by cross-border value chains is 4.27 billion tons, which is less than the scale of embodied emissions (6.32 billion tons). Emissions embodied in exported products are not necessarily enabled by foreign value added. Therefore, the scale of embodied emissions is not equal to enabled emissions. China corresponds to the largest volume ( 0.95 billion tons) of carbon emissions that are enabled by value added of other regions, such as the USA and European Union. The primary inputs supplier and the carbon emitter may not be directly connected in global supply chains. The results show that $80.40 \%$ of enabled emissions are pushed by value-added that crosses national borders once, $15.33 \%$ of enabled emissions are pushed by value-added that crosses national borders twice, $3.29 \%$ of enabled emissions are pushed by valueadded that crosses national border three times, and $0.98 \%$ of the enabled emissions are pushed by value-added that crosses national borders four times or more.

Figure 2 presents the allocation of regional carbon responsibility by a simple sankey diagram. However, Figure 2 fails to reveal the destinations of final demand that drives a country's emissions or the sources of primary inputs that enable a country's emissions. To reveal the carbon transfer between country pairs, a chord chart on bilateral carbon transfer in 2009 is presented in Appendix D. The results show that the 
largest carbon transfer of embodied emissions is from China to the USA. In addition, a large volume of China's emissions are enabled by the value added of other countries because China is located at the downstream of global value chains. A country's territory emissions can be further classified at a sectoral level (Appendix E). Although the scale of direct international electricity transfer is small, electricity is an important primary input to support the production of internationally traded industrial products. Therefore, the electricity generation sector corresponds to the largest scale of emissions that are embodied in other sectors' exports or enabled by other sectors' imports. The products of mining and heavy industry sectors are not only directly exported to other countries but are also widely used as intermediate inputs to support the production of traded products. Therefore, these countries also correspond to large scale of trade-related emissions. Finally, the transportation sectors provide transportation services to support the international trade. Therefore, the scales of embodied and enabled emissions of these three sectors are also great. The products of agriculture and service industries are mainly used to satisfy domestic final demand. Therefore, the scale of trade-related emissions are small for agricultural and service sectors (more detailed information is presented in Appendix E).

\subsection{Average length of carbon transfer}

The changing trends of average length of global carbon transfer over the period 19952009 are presented in Figure 3, as well as the changing trends of average length of selected countries' and sectors' carbon transfer. These regions and sectors all correspond to top five and top ten large scale of trade-related emissions. A greater number of average length of a region or sector's carbon transfer means that it is more difficult to replace the corresponding carbon responsibility.

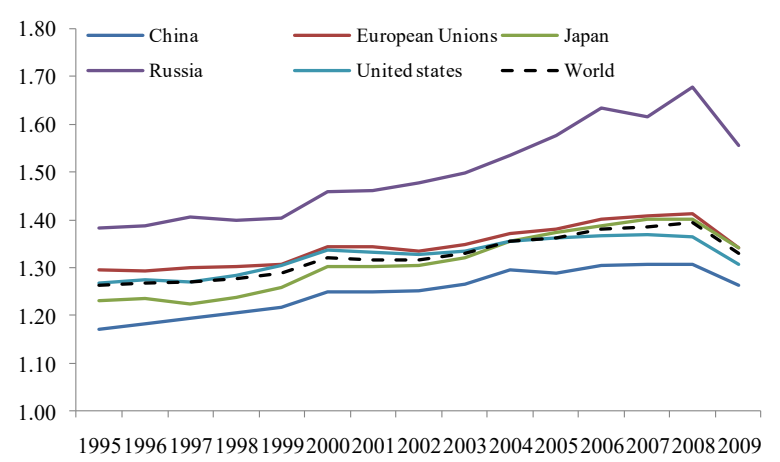

199519961997199819992000200120022003200420052006200720082009

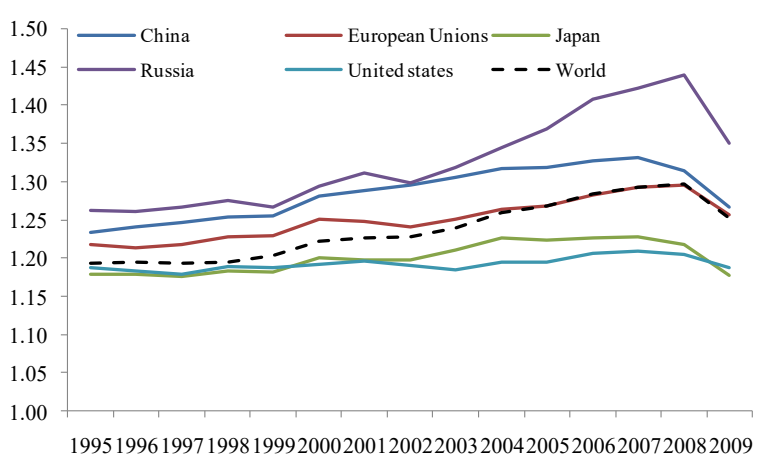

199519961997199819992000200120022003200420052006200720082009 


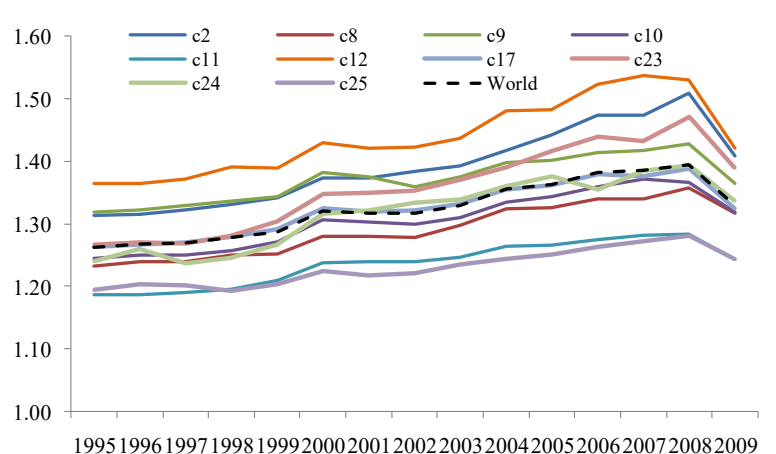

c. $A L_{-} L$ at sectorial level

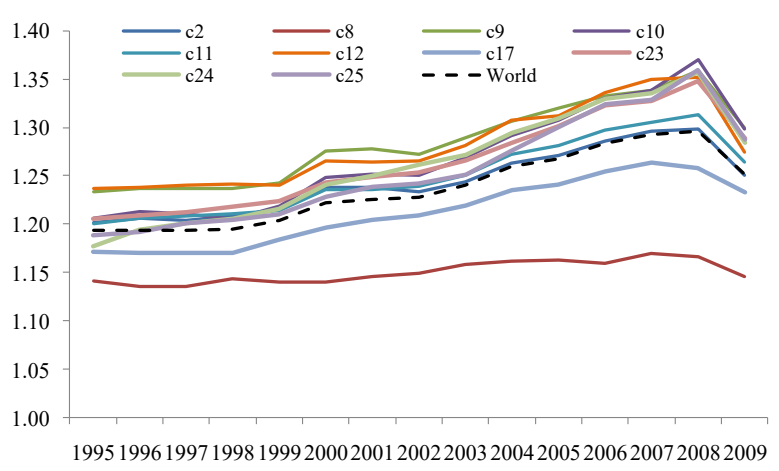

d. $A L \_G$ at sectoral level

Figure 3 Changing trend of world average length of carbon transfer

The results show that the $A L_{-} L$ associated with the world's embodied emissions is greater than the $A L_{-} G$ associated with the world's enabled emissions. This is consistent with the above finding that a smaller share of enabled emissions correspond to $\mathrm{BCF}$ that is greater than one. Carbon-intensive industries, such as electricity generation sector, tend to be located in the upstream of production chains. In other words, carbon emitters are closer to the raw material supplier than the final consumer. Therefore, $A L_{-} L$ tend to be greater than the $A L_{-} G$. With the development of global production fragmentation, the average length of carbon transfer shows a generally increasing trend over the period 1995-2008. For instance, the world $A L_{-} G$ associated with enabled emissions increased from 1.19 in 1995 to 1.30 in 2008 (robustness analysis of the average length of carbon transfer in 2008 are presented in Appendix G), which decreased to 1.25 in 2009 due to the financial crisis in 2008 . The changing trends of BCF associated with embodied and enabled emissions are almost the same. The financial crisis in 2008 also had a significantly negative impact on the world average $A L_{-} G$ associated with enabled emissions. In addition, the $A L_{-} L$ associated with embodied emissions decreased in 2009 because of the economic recession in 2008. The increasing rate of $A L_{-} G$ associated with enabled emissions also decreased 
noticeably in 2009. Ignoring the impact of the financial crisis, we could conclude that spatial production fragmentation means that it becomes increasingly more challenging to shift from PBA to CBA or IBA.

Figures 3.a and 3.b list the changing trends of average length of carbon transfer at regional level. Russia is a raw materials supplying country whose raw materials may be processed by different countries before being finally absorbed by consumers. Therefore, Russia has a great average AL_L associated with embodied emissions. China is located in the downstream of global production chains and directly exports a large scale of products to meet the final demand of other countries. Therefore, the AL_L associated with China's embodied emissions is small. A large scale of carbon emissions in the USA is enabled by raw materials from Mexico and Canada. The close economic linkage between these three countries determines that the USA corresponds to a smaller AL_G associated its enabled emissions. Similarly, Japan's emissions are also mainly enabled by raw materials imports. Russia and China's emissions are mainly enabled by imports of intermediate inputs from the developed countries. Therefore, these two countries correspond to a large AL_G associated with their enabled emissions. The AL_G associated with the European Union's enabled emissions are similar to the world average. It should be noted that the average length of carbon transfer can also be illuminated from the bilateral perspective (Appendix F).

Figures 3.c and 3.d show that there exist marked differences in average length of carbon transfer at sectoral level. Sector C12 (Basic Metals and Fabricated Metal) corresponds to the largest average $A L_{-} L$ associated with embodied emissions. This is because metal products are widely used as intermediate inputs to support the production of traded industrial products. The production process is relatively simple for sectors C25 (Air Transport) and C11 (Other Non-Metallic Mineral). Therefore, these sectors are corresponding to smaller average $A L_{-} L$ associated with embodied emissions. Sector C8 (Coke, Refined Petroleum and Nuclear Fuel) has the smallest average BCF associated with enabled emissions. This is because coal and crude oil account for a significant share in the production of sector $\mathrm{C} 8$. The production location of the coal and crude oil are strongly related to the regional resource endowment, and the production process is less spatial fragmented. Therefore, sector C8 corresponds to the lowest average $A L \_G$ associated with enabled emissions. Similarly, sector C17 (Electricity, Gas and Water Supply) also has lower average $A L_{-} G$ in Figure 3.d. The 
sectors with a greater average length of carbon transfer would face a greater challenge to shift from PBA to CBA or IBA. In addition, there is an increasing trend for the average length of carbon transfer for most sectors over the period 1995-2008. ${ }^{7}$ This phenomenon reflects that the production stages of products are fragmented among different regions. It becomes more and more challenging to shift carbon responsibility along global supply chains.

\subsection{BCF-adjusted consumption- and income-based accounting}

CBA and IBA focus on the influence of final demand and primary input supplier on the carbon emissions. However, the final consumer's (raw material supplier's) influential power on the carbon emitter may decrease exponentially with the BCF associated with embodied (enabled) emissions because of international differences in politics, economy, and culture across countries. In other words, spatial production fragmentation hinders the environmental effectiveness of CBA and IBA. This paper quantifies consumption-based and income-based national carbon emissions according to the influence-criterion, assuming $\alpha=0.5$ and $\beta=0.5$.

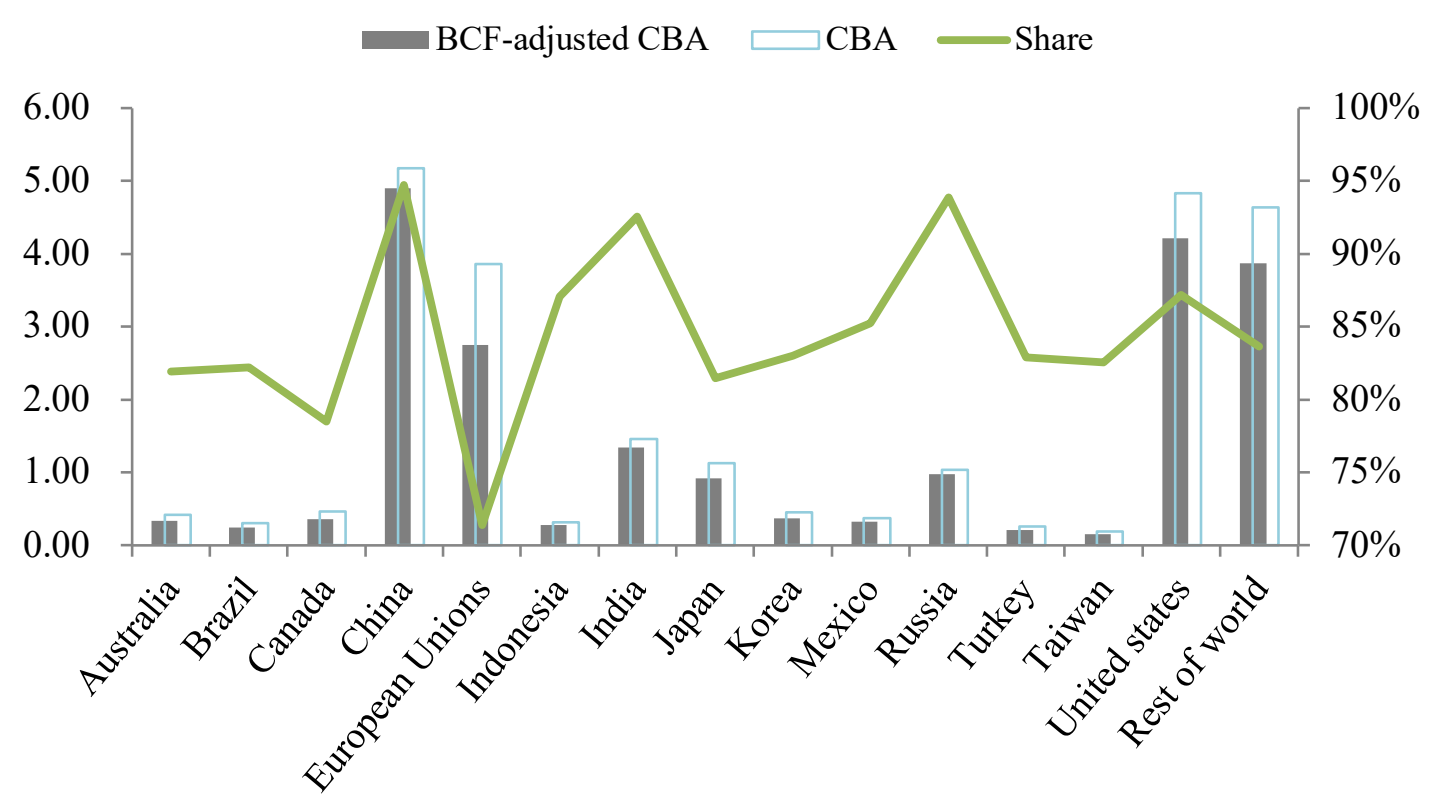

a) Consumption-based regional carbon inventories

\footnotetext{
7 The changing trends in the average BCF associated with trade-related emissions for the sector with large scale of embodied or enabled emissions are presented in Appendix F.
} 


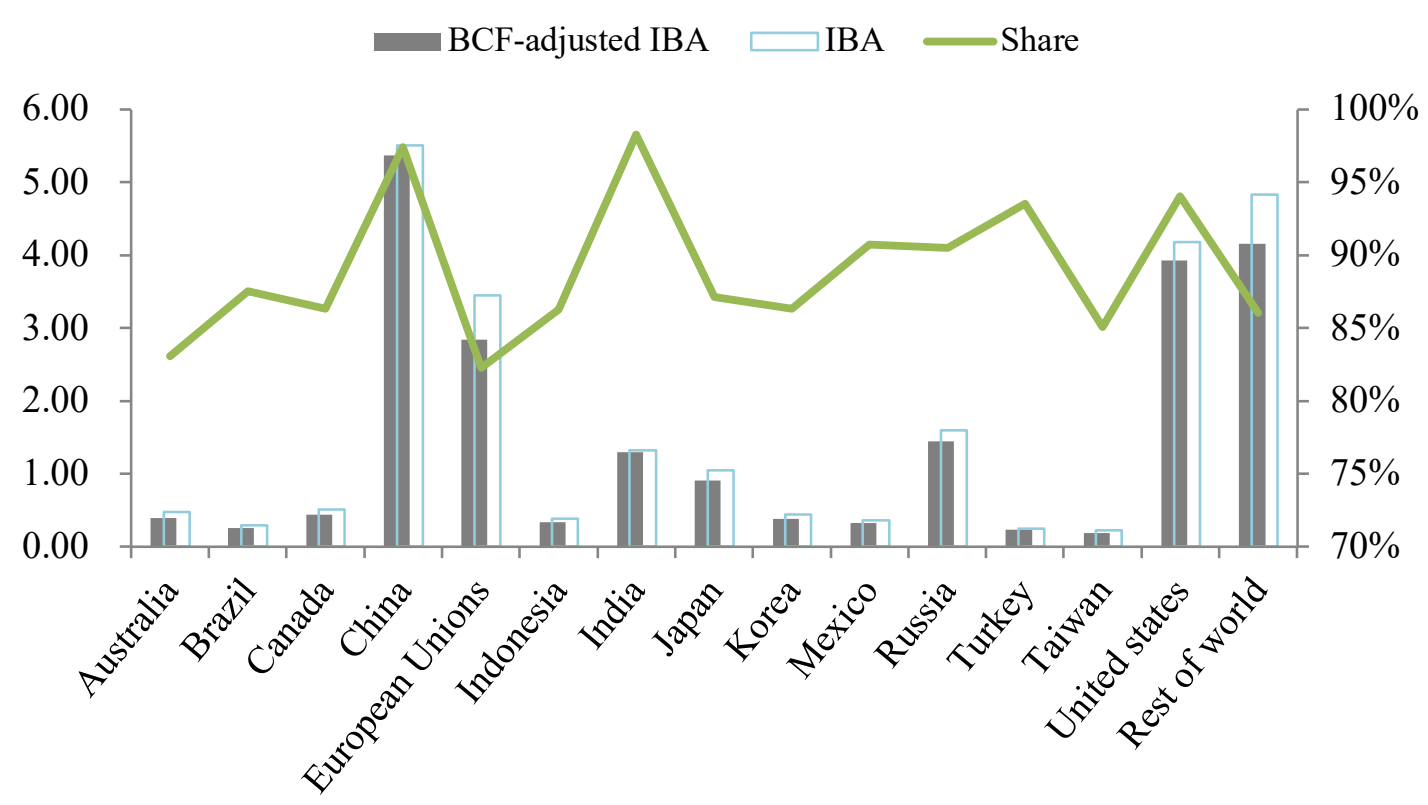

b) Income-based regional carbon inventories

Figure 4 Consumption-based and income-based regional carbon inventories taking $\mathrm{BCF}$ associated with trade-related emission into account

Under PBA, the territory emissions of a region would decrease proportionally if the region decreases the volume of output. However, the decrease of a country's final demand has a disproportionate influence on the emissions induced by this region's final demand. An explanation is the international trade substitution, which means that the carbon emitter may increase the outputs that are generated to meet other region's final demand. Similarly, the influential power of the raw material supplier on the enabled emissions would also decrease with increasing BCF associated with global value chains. This is closely related to the boundary of political power. A country only has direct control over emissions generated in its administered territory and has an indirect influence on emissions generated in other regions. Figure 4 shows that the traditional CBA and IBA tend to overestimate the influential power of final demand and raw material supplier on the carbon emitter. Spatial production fragmentation hinders the environmental effectiveness of these two carbon accounting schemes because of inconsistency with political and environmental boundaries. This problem is extremely serious for the developed countries, such as the EU. CBA can be observed as another type of border adjustment (Peters, 2008). This provides support for the assertion that trade-related climate regulations should also take border-crossing frequency associated with trade-related emissions into account (Zhang et al., 2017a; Zhang and Zhu, 2017).

The largest carbon transfer through international trade is from China to the USA (Davis and Caldeira, 2010). How do the consumption-based regulations in the USA influence the carbon emissions in China? The results show that the traditional 
intermediate and final product trade, with a BCF of 1, corresponds to the largest share (83.34\%) of carbon transfer from China to the USA. The traded products cross national borders twice. $12.81 \%$ of carbon transfer from China to the USA is through the international trade whose associated $\mathrm{BCF}$ is 2 . Trade flows that cross national borders three or more times account for $3.85 \%$ of gross carbon transfer from China to the USA. With the increase of BCF, the influential power of the USA's consumptionbased climate regulations on embodied emissions would decrease. The top 20 carbon transfer paths are presented in Table 2.

Table 2 Structural path lists for carbon transfer from China to the USA

\begin{tabular}{|c|c|c|c|c|c|}
\hline Rank & Path description & $\mathrm{BCF}$ & Volume (Mt CO2) & Coverage of path in total & Cumulative coverage \\
\hline 1 & $\mathrm{CHN} \rightarrow \mathrm{USA}$ & 1 & 293.39 & $83.34 \%$ & $83.34 \%$ \\
\hline 2 & $\mathrm{CHN} \rightarrow \mathrm{RoW} \rightarrow \mathrm{USA}$ & 2 & 13.86 & $3.94 \%$ & $87.28 \%$ \\
\hline 3 & $\mathrm{CHN} \rightarrow \mathrm{MEX} \rightarrow \mathrm{USA}$ & 2 & 8.72 & $2.48 \%$ & $89.75 \%$ \\
\hline 4 & $\mathrm{CHN} \rightarrow \mathrm{IND} \rightarrow \mathrm{USA}$ & 2 & 4.62 & $1.31 \%$ & $91.07 \%$ \\
\hline 5 & $\mathrm{CHN} \rightarrow \mathrm{CAN} \rightarrow \mathrm{USA}$ & 2 & 4.58 & $1.30 \%$ & $92.37 \%$ \\
\hline 6 & $\mathrm{CHN} \rightarrow \mathrm{KOR} \rightarrow \mathrm{USA}$ & 2 & 2.87 & $0.81 \%$ & $93.18 \%$ \\
\hline 7 & $\mathrm{CHN} \rightarrow \mathrm{JPN} \rightarrow \mathrm{USA}$ & 2 & 2.29 & $0.65 \%$ & $93.83 \%$ \\
\hline 8 & $\mathrm{CHN} \rightarrow \mathrm{TWN} \rightarrow \mathrm{USA}$ & 2 & 1.74 & $0.50 \%$ & $94.33 \%$ \\
\hline 9 & $\mathrm{CHN} \rightarrow \mathrm{DEU} \rightarrow \mathrm{USA}$ & 2 & 1.54 & $0.44 \%$ & $94.76 \%$ \\
\hline 10 & $\mathrm{CHN} \rightarrow \mathrm{RoW} \rightarrow \mathrm{IND} \rightarrow \mathrm{USA}$ & 3 & 0.98 & $0.28 \%$ & $95.04 \%$ \\
\hline 11 & $\mathrm{CHN} \rightarrow \mathrm{RoW} \rightarrow \mathrm{CHN} \rightarrow \mathrm{USA}$ & 3 & 0.80 & $0.23 \%$ & $95.27 \%$ \\
\hline 12 & $\mathrm{CHN} \rightarrow \mathrm{GBR} \rightarrow \mathrm{USA}$ & 2 & 0.79 & $0.23 \%$ & $95.49 \%$ \\
\hline 13 & $\mathrm{CHN} \rightarrow \mathrm{TWN} \rightarrow \mathrm{CHN} \rightarrow \mathrm{USA}$ & 3 & 0.64 & $0.18 \%$ & $95.68 \%$ \\
\hline 14 & $\mathrm{CHN} \rightarrow \mathrm{IDN} \rightarrow \mathrm{USA}$ & 2 & 0.60 & $0.17 \%$ & $95.85 \%$ \\
\hline 15 & $\mathrm{CHN} \rightarrow \mathrm{KOR} \rightarrow \mathrm{CHN} \rightarrow \mathrm{USA}$ & 3 & 0.57 & $0.16 \%$ & $96.01 \%$ \\
\hline 16 & $\mathrm{CHN} \rightarrow \mathrm{AUS} \rightarrow \mathrm{USA}$ & 2 & 0.55 & $0.16 \%$ & $96.16 \%$ \\
\hline 17 & $\mathrm{CHN} \rightarrow \mathrm{USA} \rightarrow \mathrm{CAN} \rightarrow \mathrm{USA}$ & 3 & 0.53 & $0.15 \%$ & $96.31 \%$ \\
\hline 18 & $\mathrm{CHN} \rightarrow \mathrm{USA} \rightarrow \mathrm{MEX} \rightarrow \mathrm{USA}$ & 3 & 0.48 & $0.14 \%$ & $96.45 \%$ \\
\hline 19 & $\mathrm{CHN} \rightarrow \mathrm{KOR} \rightarrow \mathrm{RoW} \rightarrow \mathrm{USA}$ & 3 & 0.47 & $0.13 \%$ & $96.58 \%$ \\
\hline 20 & $\mathrm{CHN} \rightarrow \mathrm{FRA} \rightarrow \mathrm{USA}$ & 2 & 0.46 & $0.13 \%$ & $96.72 \%$ \\
\hline
\end{tabular}

The results show that many countries are involved in the carbon transfer from China to the USA. The influential power of the USA's climate regulations would decrease with the increase with BCF of a carbon transfer path. For instance, the 3rd carbon transfer path shows that the traded products are first processed by Mexico and then exported to the USA. The traded products cross national borders twice. The USA's consumption-based climate regulations first influence the production activity of upstream enterprises in Mexico and then influence the economic activities in China. The 12nd carbon transfer path corresponds to greater volume of embodied emissions than the 11th carbon transfer path. However, the BCF associated with the 12nd carbon transfer path is smaller than that of the 11th carbon transfer path. This means the USA's consumption-based climate regulations may have a greater impact on embodied emissions through the 12th carbon transfer path than the 11th carbon transfer path. It should be noted that the traded products may cross national border 
between China and the USA twice or more before they are finally consumed. For instance, the 18th carbon transfer path means that the traded products are first exported from China to the USA and the traded products are first processed by Mexico before they are absorbed by the USA. The results show that global production fragmentation complicates the carbon transfer through international trade. A full picture of carbon transfer along global supply chains is necessary for the shifting between different accounting schemes. In the end, the proposed method could also be used to analyze carbon transfer between any two countries and the emissions enabled by different cross-border value chains paths. Due to space limitation, this paper will not individually discuss carbon transfer paths.

\section{Conclusions}

Regional carbon accounting is an important debate in international climate change negotiations. Consumption-based and income-based accounting schemes are often advocated as alternatives of traditional production-based accounting to reallocate carbon responsibility from a carbon emitting region to a final consuming region and raw material supplying region. However, CBA and IBA have the limitation of a wide system boundary (Peters, 2008). The development of spatial production fragmentation in recent years may further complicate the shift of national carbon accounting. This paper adopts border-crossing frequency associated with trade-related emissions to evaluate the effect of spatial production fragmentation on the shift of national carbon accounting. The main results of this study are summarized below.

First, the differences among different national carbon accounting lie in the allocation of carbon responsibility on trade-related emissions. The raw material supplying country, the carbon emitting country, and the final consuming country are not necessarily connected to one another in the cross-border supply chains. With the magnitude of embodied and enabled emissions being 6.32 billion tons and 4.27 billion tons in 2009 , as much as $25.02 \%$ of embodied emissions and $19.60 \%$ of enabled emissions crossed national borders more than once in 2009. This means that the shift among different carbon accounting schemes is not only related to the magnitude of trade related emissions but also related to border-crossing frequency associated with emissions embodied in or enabled by international trade.

Second, spatial production fragmentation makes the shift of carbon responsibility increasingly challenging. It is found that there is an increasing trend of geographical separation among the primary input supplier, carbon emitter, and final consumer over the recent decades. This trend is obviously influenced by the financial crisis of 2008 . The increasing trend of $\mathrm{BCF}$ associated with trade-related emissions means that extra steps are required for the shifting from PBA to CBA and IBA, and uncertainty 
inevitably increases. This may impact the implementation of CBA and IBA, although they may have some advantages over PBA. In addition, there exist obvious differences between $\mathrm{BCF}$ associated with trade-related emissions at the regional and sectoral levels.

Third, spatial production fragmentation reduces the effectiveness of CBA and IBA. Assuming that the final consumer's (raw material supplier's) influential power on the carbon emitter decreases exponentially with the BCF associated with embodied (enabled) emissions, we find that BCF-adjusted CBA and IBA are smaller than the traditional CBA and IBA, especially for the developed countries. This means that the traditional CBA and IBA tend to overestimate the influential power of final demand and raw material suppliers on the carbon emitter. It is suggested to increase the data quality and availability among direct and indirect trading partners. This increase in data quality and availability is extremely important for the developing countries, which are playing an increasingly important role in global supply chains. Finally, this study proposes that structural path analysis could be adopted to clarify the main carbon transfer path, with the carbon transfer from China to the USA as an example. In addition, we discuss the effect of the spatial aggregation level on the robustness of the final results.

\section{Acknowledgements}

The authors gratefully acknowledge the financial support from the National Natural Science Foundation of China (grant nos. 71690243, 71603179 and 71373055), Tianjin Program of Philosophy and Social Science (TJGL16-007Q), and Seed Foundation of Tianjin University (2017XSZ-0016). An earlier version of this paper was presented at the Annual Climate Economics Chair Conference on Climate, Energy and Development, Paris-Dauphine University, 2 October 2018. Views expressed here are those of the authors and do not necessarily reflect the views of the grant providers. The authors bear sole responsibility for any errors and omissions that may remain.

\section{References}


Afionis, S., Sakai, M., Scott, K., Barrett, J., Gouldson, A., 2017. Consumption-based carbon accounting: does it have a future? Wiley Interdiscip. Rev. Clim. Chang. 8, e438. https://doi.org/10.1002/wcc.438

Andrew, R.M., Peters, G.P., 2013. A multi-region input-output table based on the global trade analysis project database (GTAP-MRIO). Econ. Syst. Res. 25, 99 121.

Antràs, P., Chor, D., Fally, T., Hillberry, R., 2012. Measuring the upstreamness of production and trade flows. Am. Econ. Rev. 102, 412-416. https://doi.org/10.1257/aer.102.3.412

Arce, G., López, L.A., Guan, D., 2016. Carbon emissions embodied in international trade: The post-China era. Appl. Energy 184, 1063-1072. https://doi.org/10.1016/j.apenergy.2016.05.084

Davis, S.J., Caldeira, K., 2010. Consumption-based accounting of CO2 emissions. Proc. Natl. Acad. Sci. U. S. A. 107, 5687-5692. https://doi.org/10.1073/pnas.0906974107

Davis, S.J., Peters, G.P., Caldeira, K., 2011. The supply chain of CO2 emissions. Proc. Natl. Acad. Sci. U. S. A. 108, 18554-18559. https://doi.org/10.1073/pnas.1107409108//DCSupplemental.www.pnas.org/cgi/doi/10.1073/pnas.1107409108

Dietzenbacher, E., Romero, I., 2007. Production chains in an interregional framework: Identification by means of average propagation lengths. Int. Reg. Sci. Rev. 30, 362-383. https://doi.org/10.1177/0160017607305366

Dietzenbacher, E., Romero Luna, I., Bosma, N.S., 2005. Using Average Propagation Lengths to Identify Production Chains in the Andalusian Economy. Estud. Econ. Apl. 23, 405-422.

Druckman, A., Jackson, T., 2009. The carbon footprint of UK households 1990-2004: A socio-economically disaggregated, quasi-multi-regional input-output model. Ecol. Econ. 68, 2066-2077. https://doi.org/10.1016/j.ecolecon.2009.01.013

Fally, T., 2012. Production staging: measurement and facts. Working Paper. University of Colorado- Boulder.

Feng, K., Davis, S.J., Sun, L., Li, X., Guan, D., Liu, W., Liu, Z., Hubacek, K., 2013. Outsourcing CO2 within China. Proc. Natl. Acad. Sci. U. S. A. 110, 1165411659. https://doi.org/10.1073/pnas.1219918110

Gallego, B., Lenzen, M., 2005. A consistent input-output formulation of shared producer and consumer responsibility. Econ. Syst. Res. 17.

Gallego, B., Lenzen, M., 2005. A consistent input-output formulation of shared producer and consumer responsibility. Econ. Syst. Res. 17, 365-391.

Guo, J., Zhang, Z., Meng, L., 2012. China's provincial CO 2 emissions embodied in international and interprovincial trade. Energy Policy 42, 486-497.

Hertwich, E.G., Peters, G.P., 2009. Carbon footprint of nations: A global, trade-linked analysis. Environ. Sci. Technol. 43, 6414-6420. https://doi.org/10.1021/es803496a 
Jakob, M., Marschinski, R., 2012. Interpreting trade-related CO2 emission transfers. Nat. Clim. Chang. 3, 19-23. https://doi.org/10.1038/nclimate1630

Kanemoto, K., Moran, D., Lenzen, M., Geschke, A., 2014. International trade undermines national emission reduction targets : New evidence from air pollution. Glob. Environ. Chang. 24, 52-59. https://doi.org/10.1016/j.gloenvcha.2013.09.008

Lenzen, M., Kanemoto, K., Moran, D., Geschke, A., 2012. Mapping the structure of the world economy. Environ. Sci. Technol. 46, 8374-8381.

Lenzen, M., Moran, D., Kanemoto, K., Foran, B., Lobefaro, L., Geschke, A., 2012. International trade drives biodiversity threats in developing nations. Nature 486, 109-112. https://doi.org/10.1038/nature11145

Lenzen, M., Moran, D., Kanemoto, K., Geschke, A., 2013. Building EORA: A global multi-region input-output database at high country and sector resolution. Econ. Syst. Res. 25, 20-49. https://doi.org/10.1080/09535314.2013.769938

Lenzen, M., Murray, J., 2010. Conceptualising environmental responsibility. Ecol. Econ. 70, 261-270. https://doi.org/10.1016/j.ecolecon.2010.04.005

Lenzen, M., Murray, J., Sack, F., Wiedmann, T., 2007. Shared producer and consumer responsibility - Theory and practice. Ecol. Econ. 61, 27-42. https://doi.org/10.1016/j.ecolecon.2006.05.018

Liang, S., Qu, S., Zhu, Z., Guan, D., Xu, M., 2017. Income-Based Greenhouse Gas Emissions of Nations. Environ. Sci. Technol. 51, 346-355. https://doi.org/10.1021/acs.est.6b02510

Liang, S., Wang, H., Qu, S., Feng, T., Guan, D., Fang, H., Xu, M., 2016. Socioeconomic Drivers of Greenhouse Gas Emissions in the United States. Environ. Sci. Technol. 50, 7535-7545. https://doi.org/10.1021/acs.est.6b00872

Liu, L., 2014. A critical examination of the consumption-based accounting approach: Has the blaming of consumers gone too far? Wiley Interdiscip. Rev. Clim. Chang. 6, 1-8.

Marques, A., Rodrigues, J., Domingos, T., 2013. International trade and the geographical separation between income and enabled carbon emissions. Ecol. Econ. 89, 162-169. https://doi.org/10.1016/j.ecolecon.2013.02.020

Marques, A., Rodrigues, J., Lenzen, M., Domingos, T., 2012. Income-based environmental responsibility. Ecol. Econ. 84, 57-65. https://doi.org/10.1016/j.ecolecon.2012.09.010

Meng, J., Liu, J., Xu, Y., Tao, S., 2015. Tracing Primary PM2.5 emissions via Chinese supply chains. Environ. Res. Lett. 10, 54005. https://doi.org/10.1088/1748-9326/10/5/054005

Muradov, K., 2016. Counting borders in global value chains ${ }^{\circ}$. Available SSRN $\mathrm{http} / / \mathrm{ssrn} . \mathrm{com} / \mathrm{abstract}=2808130$.

Ni, H., Gong, L., Xia, J., 2016. The evolution path of production fragmentation and its factors. Manage. World 4, 10-23. 
Oosterhaven, J., Bouwmeester, M.C., 2013. The Average Propagation Length: Conflicting Macro, Intra-industry, and Interindustry Conclusions. Int. Reg. Sci. Rev. 36, 481-491. https://doi.org/10.1177/0160017613486670

Peters, G.P., 2008. From production-based to consumption-based national emission inventories. Ecol. Econ. 65, 13-23. https://doi.org/10.1016/j.ecolecon.2007.10.014

Peters, G.P., Hertwich, E.G., 2008a. Post-Kyoto greenhouse gas inventories: Production versus consumption. Clim. Change 86, 51-66. https://doi.org/10.1007/s10584-007-9280-1

Peters, G.P., Hertwich, E.G., 2008b. CO 2 Embodied in International Trade with Implications for Global Climate Policy. Environ. Sci. Technol. 42, 1401-1407. https://doi.org/10.1021/es072023k

Peters, G.P., Hertwich, E.G., 2007. Structural analysis of international trade: environmental impacts of Norway. Econ. Syst. Res. 18, 155-181.

Peters, G.P., Minx, J.C., Weber, C.L., Edenhofer, O., 2011. Growth in emission transfers via international trade from 1990 to 2008. Proc. Natl. Acad. Sci. U. S. A. 108, 8903-8908. https://doi.org/10.1073/pnas.1006388108

Skelton, A., Guan, D., Peters, G.P., Crawford-brown, D., 2011. Mapping Flows of Embodied Emissions in the Global Production System. Environ. Sci. Technol. 45, 10516-10523.

Steininger, K.W., Lininger, C., Meyer, L.H., Munoz, P., Schinko, T., 2016. Multiple carbon accounting to support just and effective climate policies. Nat. Clim. Chang. 6, 35-41. https://doi.org/10.1038/nclimate2867

Su, B., Ang, B.W., 2014. Input-output analysis of CO 2 emissions embodied in trade : A multi-region model for China. Appl. Energy 114, 377-384. https://doi.org/10.1016/j.apenergy.2013.09.036

$\mathrm{Su}, \mathrm{B}$., Ang, B.W., 2011. Multi-region input-output analysis of $\mathrm{CO} 2$ emissions embodied in trade: The feedback effects. Ecol. Econ. 71, 42-53. https://doi.org/10.1016/j.ecolecon.2011.08.024

$\mathrm{Su}, \mathrm{B} .$, Ang, B.W., 2010. Input-output analysis of $\mathrm{CO} 2$ emissions embodied in trade: The effects of spatial aggregation. Ecol. Econ. 70, 10-18. https://doi.org/10.1016/j.ecolecon.2010.08.016

Su, B., Huang, H.C., Ang, B.W., Zhou, P., 2010. Input-output analysis of CO2 emissions embodied in trade: The effects of sector aggregation. Energy Econ. 32, 166-175. https://doi.org/10.1016/j.eneco.2009.07.010

Timmer, M.P., Dietzenbacher, E., Los, B., Stehrer, R., de Vries, G.J., 2015. An Illustrated User Guide to the World Input-Output Database: The Case of Global Automotive Production. Rev. Int. Econ. 23, 575-605. https://doi.org/10.1111/roie.12178

Turner, K., Munday, M., McIntyre, S., Jensen, C.D., 2011. Incorporating jurisdiction issues into regional carbon accounts under production and consumption 
accounting principles. Environ. Plan. A 43, 722-741.

https://doi.org/10.1068/a43234

Wang, Z., Wei, S.-J., Yu, X., Zhu, K., 2017. Characterizing Global and Regional Manufacturing Value Chains: Stable and Evolving Features. Work. Pap. Sources http//dagliano.unimi.it/wp-content/uploads/2017/01/WP2017_419.pdf.

Wang, Z., Wei, S.-J., Yu, X., Zhu, K., 2014. Characterizing Patterns of Global and Regional Manufacturing Value Chains: Stable and Evolving Features.

Wang, Z., Wei, S.-J., Zhu, K., 2015. Quantifying international production sharing at the bilateral and sector levels. Work. Pap. Sources http//scholar.harvard.edu/files/jorgenson/files/zhi_wang_wwz-mar-7-2014.pdf. https://doi.org/10.3386/w19677

Weber, C.L., Matthews, H.S., 2007. Embodied environmental emissions in U.S. international trade, 1997-2004. Environ. Sci. Technol. 41, 4875-4881. https://doi.org/10.1021/es0629110

Weber, C.L., Peters, G.P., Guan, D., Hubacek, K., 2008. The contribution of Chinese exports to climate change. Energy Policy 36, 3572-3577. https://doi.org/10.1016/j.enpol.2008.06.009

Zhang, Z., 2012a. Competitiveness and Leakage Concerns and Border Carbon Adjustments. Int. Rev. Environ. Resour. Econ. 6, 225-287. https://doi.org/10.1561/101.00000052

Zhang, Z.X., 2012b. Who should bear the cost of China's carbon emissions embodied in goods for exports?. Miner. Econ. 24, 103-117. https://doi.org/10.1007/s13563-011-0012-7

Zhang, Z., Guo, J., Hewings, G.J.D., 2014. The effects of direct trade within China on regional and national $\mathrm{CO} 2$ emissions. Energy Econ. 46, 161-175. https://doi.org/10.1016/j.eneco.2014.09.011

Zhang, Z., Zhu, K., 2017. Border carbon adjustments for exports of the United States and the European Union: Taking border-crossing frequency into account. Appl. Energy 201, 188-199. https://doi.org/10.1016/j.apenergy.2017.05.065

Zhang, Z., Zhu, K., Hewings, G.J.D., 2017a. The effects of border-crossing frequencies associated with carbon footprints on border carbon adjustments. Energy Econ. 65, 105-114. https://doi.org/10.1016/j.eneco.2017.04.017

Zhang, Z., Zhu, K., Hewings, G.J.D., 2017b. A multi-regional input-output analysis of the pollution haven hypothesis from the perspective of global production fragmentation. Energy Econ. 64, 13-23. https://doi.org/10.1016/j.eneco.2017.03.007 
Appendix A. the abbreviations of 41 countries or regions in the database and country group classification

\begin{tabular}{|c|c|c|c|c|c|c|c|c|}
\hline Nations & Abbreviation & European Union & Nations & Abbreviation & European Union & Nations & Abbreviation & European Union \\
\hline Australia & AUS & & France & FRA & $\sqrt{ }$ & Malta & MLT & $\sqrt{ }$ \\
\hline Austria & AUT & $\sqrt{ }$ & United Kingdom & GBR & $\sqrt{ }$ & Netherlands & NLD & $\sqrt{ }$ \\
\hline Belgium & BEL & $\sqrt{ }$ & Greece & GRC & $\sqrt{ }$ & Poland & POL & $\sqrt{ }$ \\
\hline Bulgaria & BGR & $\sqrt{ }$ & Hungary & HUN & $\sqrt{ }$ & Portugal & PRT & $\sqrt{ }$ \\
\hline Brazil & BRA & & Indonesia & IDN & & Romania & ROM & $\sqrt{ }$ \\
\hline Canada & CAN & & India & IND & & Russia & RUS & \\
\hline China & $\mathrm{CHN}$ & & Ireland & IRL & $\sqrt{ }$ & Slovak Republic & SVK & $\sqrt{ }$ \\
\hline Cyprus & CYP & $\sqrt{ }$ & Italy & ITA & $\sqrt{ }$ & Slovenia & SVN & $\sqrt{ }$ \\
\hline Czech Republic & CZE & $\sqrt{ }$ & Japan & JPN & & Sweden & SWE & $\sqrt{ }$ \\
\hline Germany & DEU & $\sqrt{ }$ & Korea & KOR & & Turkey & TUR & \\
\hline Denmark & DNK & $\sqrt{ }$ & Lithuania & LTU & $\sqrt{ }$ & Taiwan & TWN & \\
\hline Spain & ESP & $\sqrt{ }$ & Luxembourg & LUX & $\sqrt{ }$ & United states & USA & \\
\hline Estonia & EST & $\sqrt{ }$ & Latvia & LVA & $\sqrt{ }$ & Rest of world & RoW & \\
\hline Finland & FIN & $\sqrt{ }$ & Mexico & MEX & & & & \\
\hline
\end{tabular}

\section{Appendix B. the 35 sectors in the inter-country input-output table}

\begin{tabular}{ll}
\hline Index & Sectors \\
\hline c1 & Agriculture, Hunting, Forestry and Fishing \\
c2 & Mining and Quarrying \\
c3 & Food, Beverages and Tobacco \\
c4 & Textiles and Textile Products \\
c5 & Leather, Leather and Footwear \\
c6 & Wood and Products of Wood and Cork \\
c7 & Pulp, Paper, Paper, Printing and Publishing \\
c8 & Coke, Refined Petroleum and Nuclear Fuel \\
c9 & Chemicals and Chemical Products \\
c10 & Rubber and Plastics \\
c11 & Other Non-Metallic Mineral \\
c12 & Basic Metals and Fabricated Metal \\
c13 & Machinery, Nec \\
c14 & Electrical and Optical Equipment \\
c15 & Transport Equipment \\
c16 & Manufacturing, Nec; Recycling \\
c17 & Electricity, Gas and Water Supply \\
c18 & Construction \\
c19 & Sale, Maintenance and Repair of Motor Vehicles and Motorcycles; Retail Sale of Fuel \\
c20 & Wholesale Trade and Commission Trade, Except of Motor Vehicles and Motorcycles \\
c21 & Retail Trade, Except of Motor Vehicles and Motorcycles; Repair of Household Goods \\
c22 & Hotels and Restaurants \\
c23 & Inland Transport \\
c24 & Water Transport \\
c25 & Air Transport \\
\hline
\end{tabular}




\begin{tabular}{ll}
\hline c26 & Other Supporting and Auxiliary Transport Activities; Activities of Travel Agencies \\
c27 & Post and Telecommunications \\
c28 & Financial Intermediation \\
c29 & Real Estate Activities \\
c30 & Renting of M\&Eq and Other Business Activities \\
c31 & Public Admin and Defence; Compulsory Social Security \\
c32 & Education \\
c33 & Health and Social Work \\
c34 & Other Community, Social and Personal Services \\
c35 & Private Households with Employed Persons \\
\hline
\end{tabular}


Appendix C. Decomposition of national carbon inventories under PBA, CBA and IBA

According to equations (2a) and (2b), the regional carbon emissions are divided into two parts by whether the emissions are induced by or enabled by international trade. The calculation results are presented in Figure C.1.

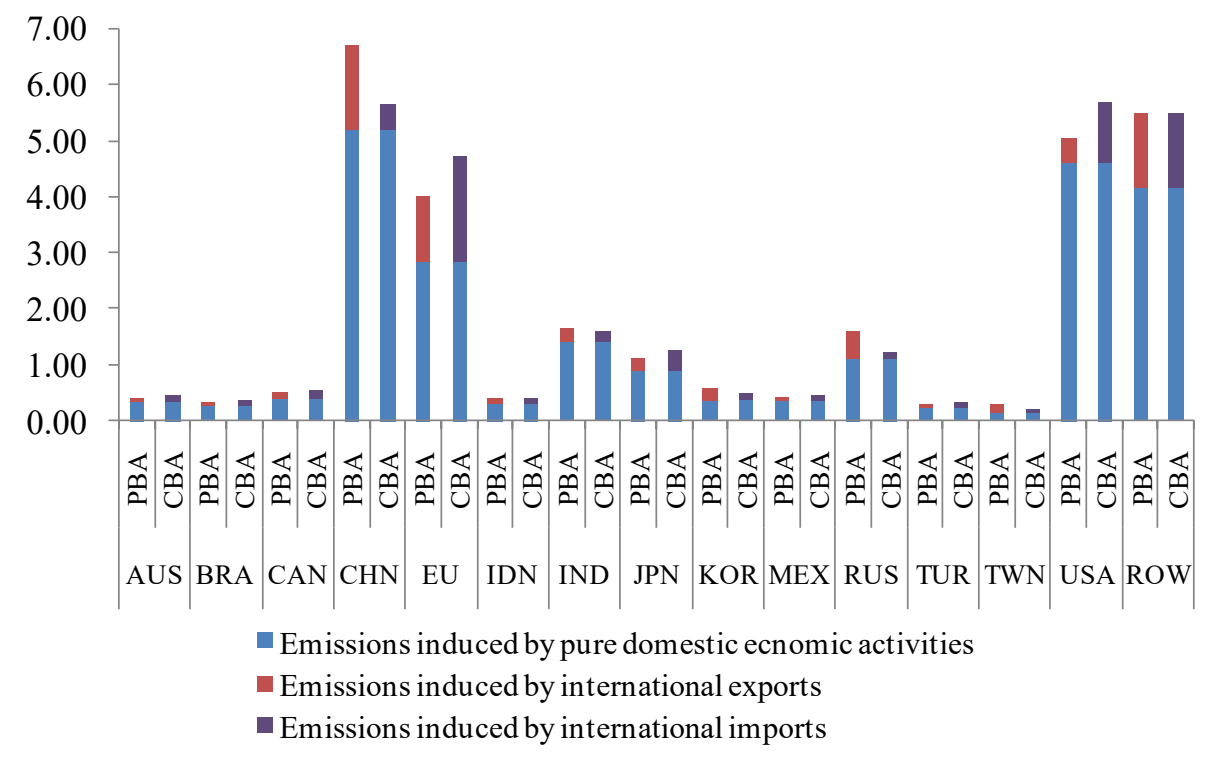

a) National emissions from production-based to consumption-based accounting

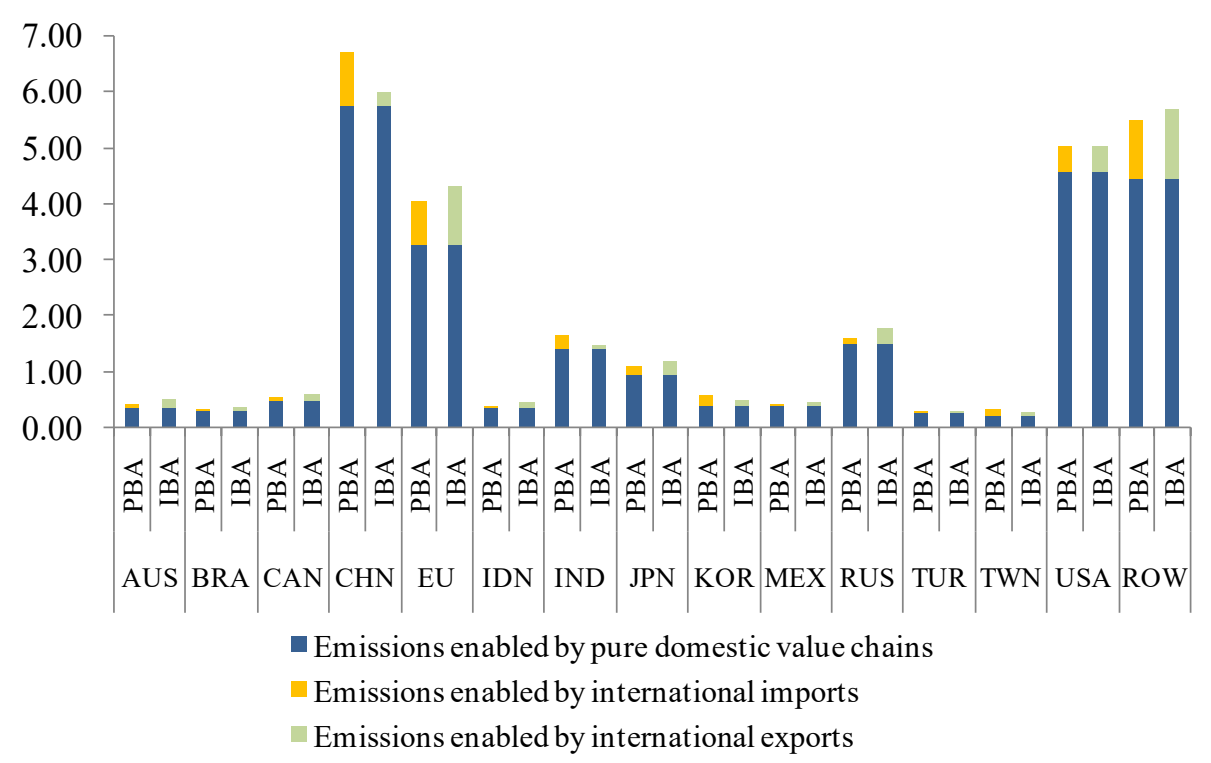

b) National emissions from production-based to income-based accounting

Figure C.1 National emission from production-based to consumption-based and income-based accounting in 2009

Figure C.1.a divides regional emissions under production-based accounting into the part that is induced by pure domestic economic activities and the part that are induced 
by international exports. Only the first part is also covered by the regional emissions under CBA, which also covers emissions induced by international imports. The results show that developing countries tend to be net carbon exporters and CBA will reduce the carbon responsibility of the developing countries. By comparison, the developed countries tend to be net carbon importers, which would face greater carbon responsibility under CBA than the condition under PBA. Being in line with the literature, the net carbon transfer direction is from the developing countries to the developed countries. Figure C1.b shows that regional emissions that are enabled by pure domestic value chains are both covered by PBA and CBA, simultaneously. Emissions enabled by international imports and exports are covered by PBA and IBA, respectively. It should be noted that emissions that are enabled by pure domestic value chains are different from the emissions that are induced by pure domestic economic activities. For instance, the former includes emissions embodied in exported final exports, but not the latter.

Appendix D. The sources and destinations of carbon transfer

From the upstream perspective, we could find the sources of primary inputs (or value added) that enable a country's emissions. This upstream decomposition process reflects the shifting from PBA to IBA. The downstream decomposition illuminates the destination of final demand that drives a country's emissions. This process reflects the shifting from PBA to CBA. The sources and destinations of trade-related emissions are presented in Figure D.1.

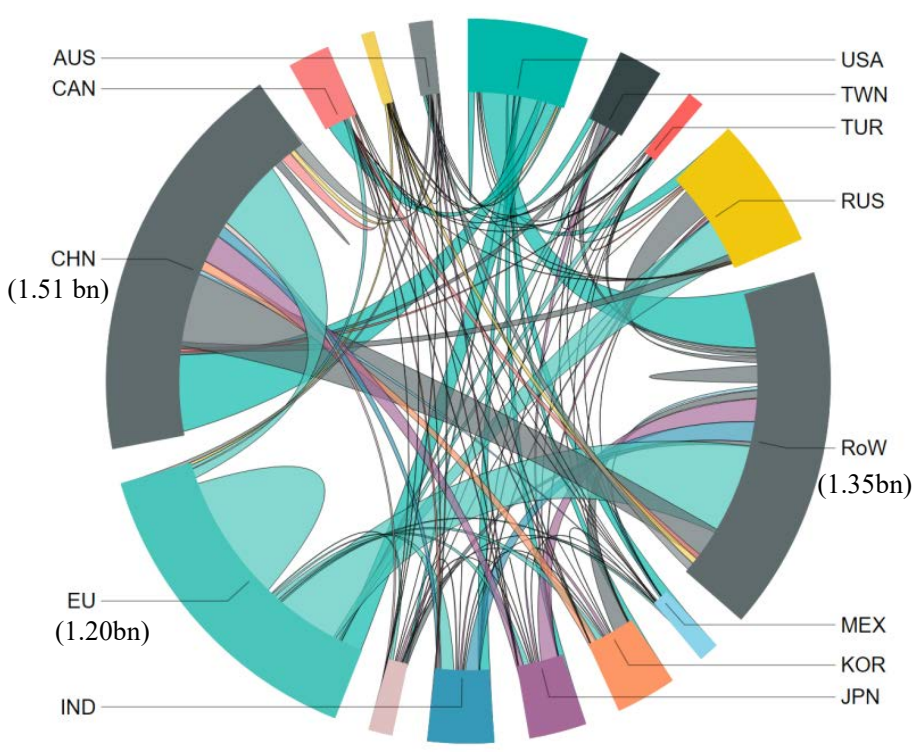

a) Embodied emissions

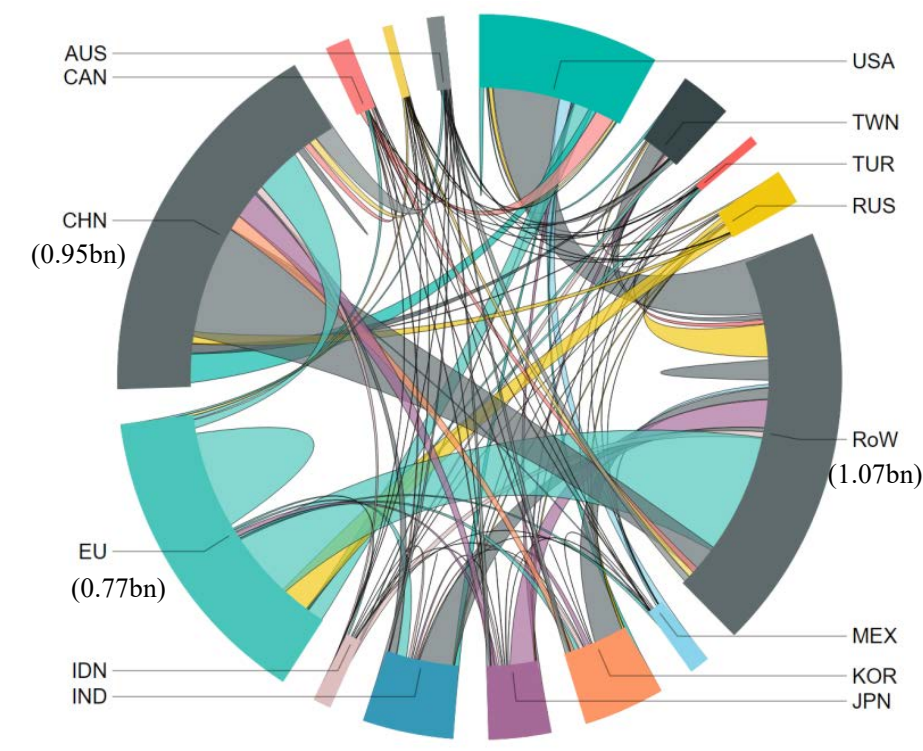

b) Enabled emissions

Figure D.1 Sources and destinations of trade-related emissions 
The magnitude of trade-related emissions is represented by chord charts. The area of each part of the circle represents the volume of each region's enabled (right) or embodied (left) emissions. The color of the chord indicates which country is the dominant driver of trade-related emissions. If a chord connects back to itself, it means that a country's value added drives its emissions through global supply chains (right) or that a country's final demand drives its emissions through global supply chains (left). Figure D.1.a shows that China is the largest carbon exporter (1.51 billion tons), which are mainly driven by the final demand of developed countries. The largest net carbon transfer is from China to the USA ( 0.32 billion tons), followed by the carbon transfer from China to the EU ( 0.28 billion tons). Figure D.1.b shows that 0.95 tons of carbon emissions in China are enabled by raw materials supplied by other countries, such as the USA and European Union. As the world factory, China mainly implements the assembling process. Research and development are usually finished in the developed countries. China is still located at the downstream of global value chains. Therefore, a large scale of China's emissions are enabled by the primary inputs of other countries. The corresponding carbon responsibility would be transferred from China to these countries when the carbon accounting scheme shift from PBA to IBA. On the contrary, Russia exports large scale of raw materials to support the production of other countries, such as China and European Union. Therefore, Russia would bear extra carbon responsibility under IBA than the condition under PBA.

Appendix E. Trade-related emissions at sectoral level

This section analyzes trade-related emissions from the sectoral perspective. It should be noted that a sector's trade-related emissions can be viewed from two angles. For instance, we could analyze a sector's emissions generated to support the production of all exports or all emissions generated to support the exports of a sector. This paper focuses on the emitting sector, rather than the exporting sector. Therefore, this section discusses a sector's both direct and indirect emissions that are related to international trade. The calculation results are presented in Figure E.1. 


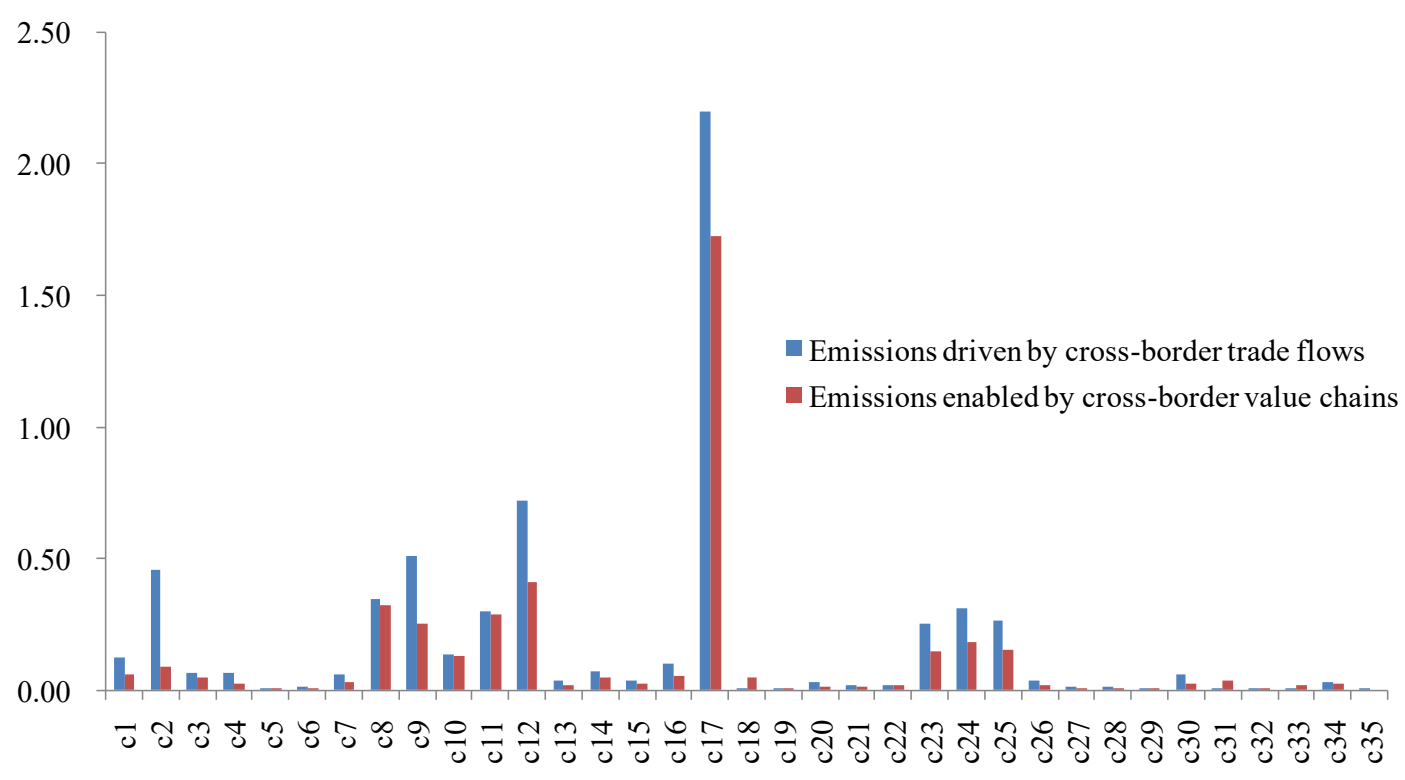

Figure E.1 Sectoral emissions related to international trade (billion tons)

The results show that international trade mainly promotes carbon emissions of the electricity generation sector (C17). 2.20 billion tons of carbon emissions of the electricity generation sector are induced by cross-border trade flows, and 1.72 billion tons of carbon emissions of the electricity generation sector are enabled by crossborder value chains. The products of sectors c2, c8, c9, c11 and c12 are not only directly exported to other countries but also widely used as intermediate inputs to support the production of traded products. Therefore, these sectors are also corresponding to large scale of trade-related emissions. For instance, the volume of embodied and enabled emissions of the chemical sector (C9) reach 0.51 and 0.25 billion tons. The transportation sectors (c23, c24, and c25) provide transportation service to support the international trade. Therefore, the scales of embodied and enabled missions of these three sectors are also great. The products of agriculture and service industries are mainly used to satisfy domestic final demand. Therefore, the scale of trade-related emissions is small for agriculture and service sectors.

Appendix F. Trade-related emissions as bilateral level

Tracing trade-related emissions along global supply chains, we could illuminate the destination of final demand that drives a country's emissions and finds the sources of primary inputs (or value added) that enable a country's emissions. The BCF associated with trade-related emissions at the bilateral perspective are presented by heat maps in Figure F.1. 


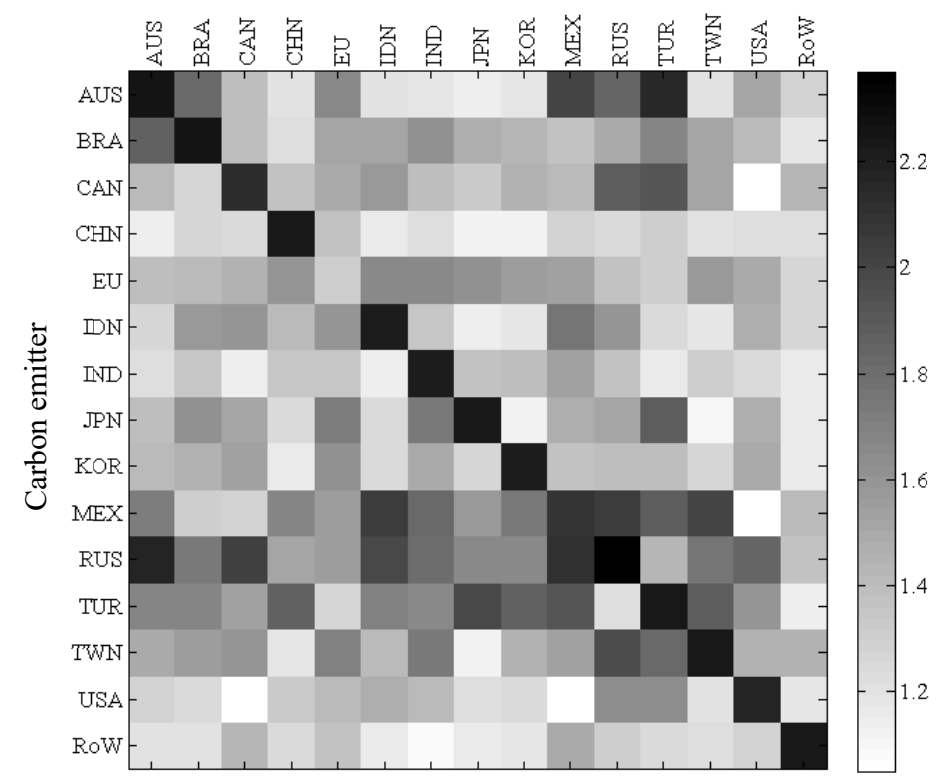

a) BCF associated with embodied emissions

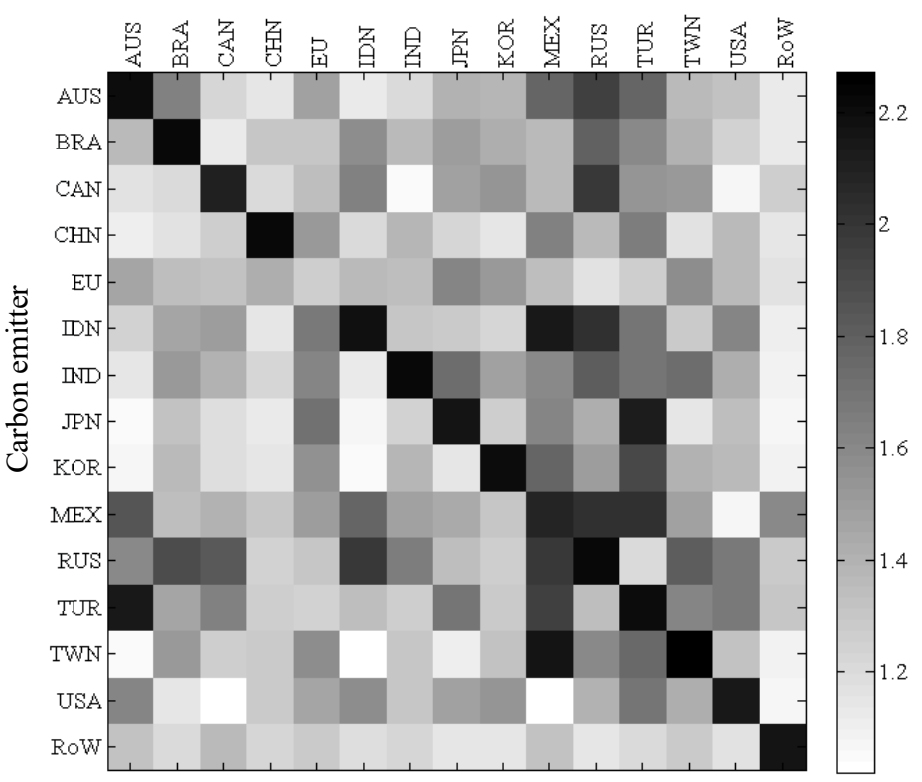

b) BCF associated with enabled emissions

Figure F.1 BCF associated with trade-related emissions at bilateral level

The average BCF associated with emissions embodied in bilateral trade are presented in Figure F.1.a (left). The results show that it is practically easier for the shifting from PBA to CBA among the countreis that are belong to the same trade area. For instance, the US, Canada, and Mexico are three countries that are located in North America and are closely linked through international trade. These three countries make up of the North America Free Trade Area. The BCFs associated with carbon transfer from Mexico and Canada to the USA are only 1.05 and 1.07. Similarly, the BCFs associated with carbon transfer among Asian countries also tend to be small, such as embodied emissions among China, Korea, Japan, and Taiwan. Figure F.1.b (right) use average BCF associated with enabled emissions to illuminate the difficulty of shifting carbon responsibility from carbon emitters to value-added suppliers. The diagonal elements are relatively greater because raw materials need to cross national borders at least twice before they return to the exporting countries. The countries that are directly linked in the global supply chain tend to have smaller BCF associated with enabled emissions. For instance, large scale of the primary inputs of Canada is directly exported to the USA and the associated BCF is only 1.03.

Appendix G. Robustness analysis of BCF associated with embodied and enabled emission in 2008

The literature shows that sectoral and spatial aggregation has obvious impacts on the measurement of trade-related emissions ( $\mathrm{Su}$ et al., 2010; Su and Ang, 2010). The sectoral level ( 35 sectors) of this study is close to the sectoral level (approximately 40 sectors) suggested by Su et al. (2010). Therefore, this paper focuses primarily on the 
effect of spatial aggregation level on the calculation of BCF associated with traderelated emissions. An inter-country input-output table with a more detailed classification at a spatial level is more suitable for the calculation of border-crossing because the spatial aggregation will ignore the border crossing among countries that are aggregated. The Eora multi-regional input-output table (Lenzen et al., 2013) covers as much as 190 countries or regions, which is significantly greater than that (41 countries or regions) of the WIOD. Considering that international trade decreased quickly in 2009 due to the financial crisis, this paper compares the BCF associated with trade-related emissions in 2008 based on two different databases (WIOD and Eora). The calculation results are presented in Figure G.1.

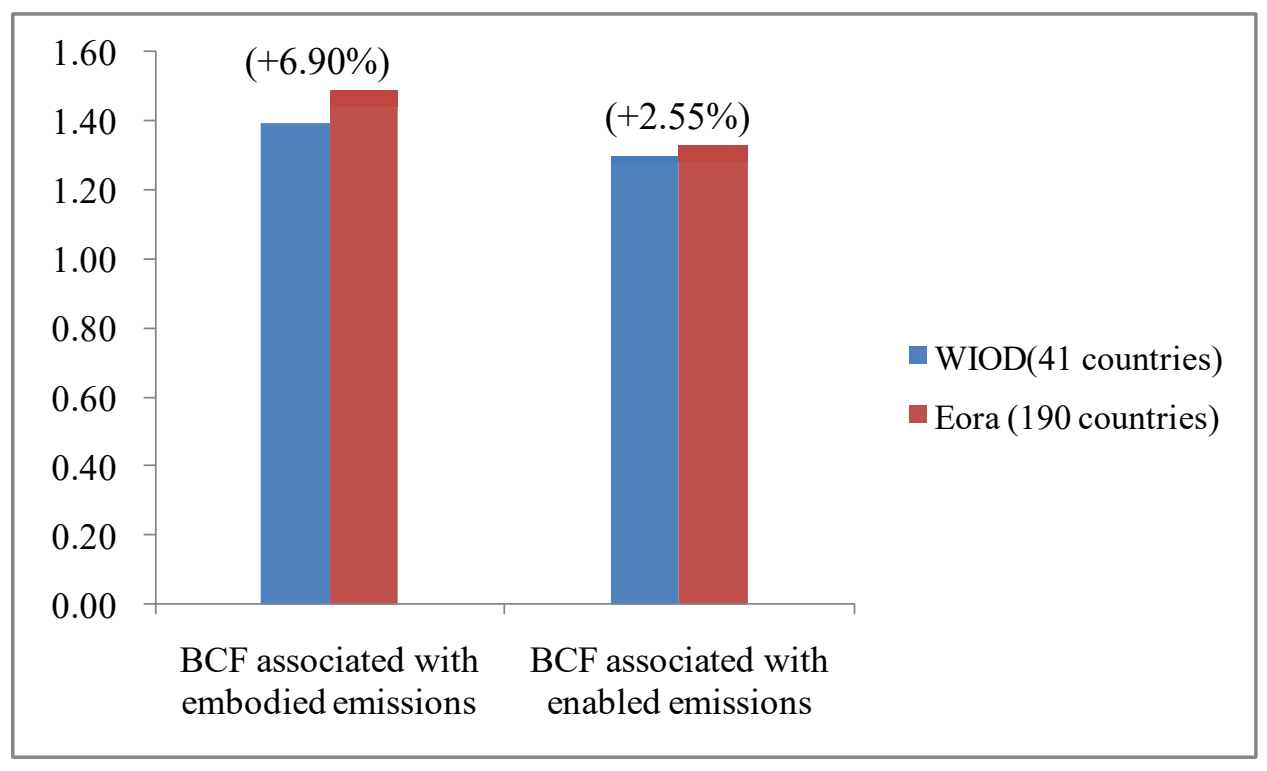

Figure G.1 BCF associated with trade-related emissions in 2008 under WIOD and Eora

Based on the Eora database, we not only analyze border crossing among the 40 countries or regions that are covered by the WIOD database but also the border crossing among 149 countries that are aggregated into the rest of world. Therefore, Figure G.1 shows that the world average BCF associated with embodied and enabled emissions increases by $6.90 \%$ and $2.55 \%$, respectively. Although the scale of countries increases by more than four times, the degree of increase in BCF is limited. This is because the 40 countries covered by WIOD play the most significant roles in international trade. For instance, these countries account for $85.80 \%$ of world's gross GDP and $80.54 \%$ of world's gross carbon emissions in 2008. If policy makers are focused mainly on border crossing among these big countries, the WIOD database may be suitable. However, policy makers should keep in mind that using this database tends to underestimate the BCF associated with trade-related emissions. 